\title{
Sistema Lupo, un Método Educativo desde la Arquitectura. Pensar y Aprender Haciendo
}

\author{
Sistema Lupo, an Educational Method from Architecture. \\ Thinking and Learning by Doing
}

\section{Sistema Lupo, um Método Educativo a partir da Arquitetura. Pensar e Aprender Fazendo}

\author{
Fermín González Blanco * \\ Ie University | Universidad Internacional
}

\begin{abstract}
Sistema Lupo es un método didáctico nacido desde la arquitectura. Se sintetizan en este texto las metodologías y fuentes seguidas que configuran una filosofía híbrida donde se entremezclan el constructivismo social, el objetivismo e incluso el materialismo filosófico. Lupo es pensar y hacer, es learning by doing, es teoría y práctica, es pensar con las manos. Una experiencia pedagógica activa basada en el acto constructivo y mental, donde los bloques de construcción de diferentes materiales y tamaños constituyen una herramienta fundamental sobre la que tejer una red de conocimientos y experiencias que nos hacen viajar desde el objeto a la ciudad, desde la vanguardia a la tradición, desde lo abstracto a lo figurativo.
\end{abstract}

Descriptores: Arquitectura, Juego educativo, Juguete educativo, Dinámica de grupo, Transferencia de conocimientos.

Sistema Lupo is a didactic method born from architecture. In this text are synthesized the methodologies and sources followed. Together they form a hybrid philosophy, where social constructivism, objectivism and even philosophical materialism are intermingled. Lupo is to think and to do, it is learning by doing, it is thinking with hands. It is an active pedagogical experience based on the constructive and mental act where building blocks of different materials and sizes constitute a fundamental tool on which a network of knowledge and experiences, that can make us travel from the object to the city, from the avant-garde to tradition or from abstraction to figuration.

Keywords: Architecture, Educational game, Educational toy, Group dynamics, Knowledge transfer.

O Sitema Lupo é um método didático nascido na Arquitetura. Neste artigo são sintetizadas as metodologias e as fontes que foram seguidas para criar uma metodologia hibrida em que se mistura o construtivismo social, o objetivismo com o materialismo filosófico. Lupo é pensar e fazer, learnign by doing, é teoría e prática, é pensar com as mãos. Uma experiência pedagógica activa baseada no acto construtor e mental onde os blocos de construções de diferentes materiais e tamanhos constituem uma ferramenta fundamental sobre a qual tecer uma rede de conhecimento e experiências que fazem viajar do objecto até a cidade, da vanguarda até à tradição, do abstracto ao figurativo

Palavras-chave: Arquitectura, Jogo educativo, Brinquedo educativo, Dinâmica de grupo, Transferência de conhecimento.

*Contacto: correo@ferminblanco.com

ISSN: 2254-3139

www.rinace.net/riejs/

revistas.uam.es/riejs
Recibido: $\quad 21$ de diciembre 2016

$1^{\text {a }}$ Evaluación: 30 de enero 2017

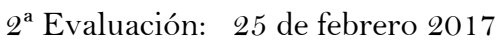

Aceptado: 1 de marzo 2017 
Me lo contaron y lo olvidé; lo vi y lo entendí; lo hice y

lo aprendí. (Confucio, 551 a. C. - 479 a. C.)

\section{Introducción}

La libertad personal, la fuerza del individuo frente a la sociedad, la teoría y la práctica, la investigación, el juego, la colaboración, el proyecto, la seriación, etc. Todos estos conceptos han servido para guiar un proyecto de investigación, de búsqueda y acción que bajo el común nombre de Sistema Lupo ha desarrollado numerosos talleres, productos, y experiencias donde arquitectura y educación han estado siempre presentes pero abiertos a muchas otras expresiones de arte y conocimiento.

Tratando de contribuir en este número de educación y justicia social, el artículo repasa todo el proceso seguido hasta el momento actual. Analiza el desarrollo metodológico del proyecto desde su aplicación inicial a su transformación en método generalizable gracias a la colaboración con otros centros y equipos. Se analizan las conclusiones parciales de cada una de estas fases y finalmente se incluyen unos ejemplos que influyen en la filosofía del proyecto. Son fuentes diversas procedentes de la arquitectura, el arte, el pensamiento o la industria que abastecen el proyecto nutriéndolo de contenido teórico y práctico.

Fruto de toda la experiencia también se han obtenido unas conclusiones comunes desde el punto de vista del usuario pero también unas conclusiones internas que afectan al propio equipo, ¿habrá otra forma de enseñar sino es aprendiendo al mismo tiempo?

\section{La protohistoria. La génesis de Sistema Lupo}

Serán varias las causas que de modo simultáneo deriven en el inicio de esta investigación y que condicionen su orientación y posterior desarrollo.

Fisac Huesos VariOs ${ }^{1}$ fue una exposición homenaje al arquitecto manchego Miguel Fisac que desde 2007 recorre gran parte de la geografía nacional divulgando los valores de la arquitectura y la ingeniería, también del patrimonio contemporáneo y del trabajo interdisciplinar. Su paso por diferentes museos genera el encargo de desarrollar una didáctica para niños que muestre estos valores. Paralelamente la candidatura impulsada desde el ayuntamiento de A Coruña para la inclusión de la torre de Hércules en el listado de obras Patrimonio de la Humanidad ofrecerá la posibilidad de desarrollar una serie de proyectos de carácter didáctico donde la seriación, la actividad manipulativa de bloques (primero eran cajas de marisco) y el trabajo en equipo derivará en Sistema Lupo.

Huesos VariOs constituye la fase divulgativa de la tesis doctoral "Los huesos de Fisac, la búsqueda de la pieza ideal2". El núcleo de esta investigación se centra en el metódico trabajo realizado por el arquitecto Miguel Fisac en el campo de la industrialización. Durante toda su trayectoria profesional Fisac proyectó, fabricó e incluso trató de

\footnotetext{
1 Mas información de la exposición comisariada por Fermín Blanco en la web http://ferminblanco.com/web/?page_id=221 A esta exposición se suman otras investigaciones en el campo de los procesos comunitarios Arquitectura EnTera http://ferminblanco.com/web/?page_id=366 y Penamoa el silencio del que sabe. http://ferminblanco.com/web/?page_id=418

${ }^{2}$ La tesis fue defendida en la Universidad Politécnica de Madrid en 2010 y a continuación fue premiada en la VIII Bienal Internacional de Arquiatesis (2010/11).
} 
introducir en el mercado una serie de piezas de hormigón con secciones huecas, que denominó "huesos" y que pretendían resolver todos los condicionantes de la construcción en una solución única. Para ello, Fisac desbordó los límites de su profesión y recurrió a técnicas propias de la ingeniería. Se salió de la academia para introducirse en el mercado y cultivó una presencia social en prensa para divulgar sus ideas sobre la arquitectura y su compromiso con la sociedad.

Gran parte de la experiencia que se muestra en este artículo no es sino el intento de aplicar algunos de estos principios en un proyecto aparentemente alejado del mundo de la arquitectura industrializada pero que mantiene un hilo conductor deudor de esta historia. La arquitectura, la sociedad, la teoría y la práctica, la acción. También el trabajo en equipo y la creatividad siempre asociada a nuestra profesión (figura 1).
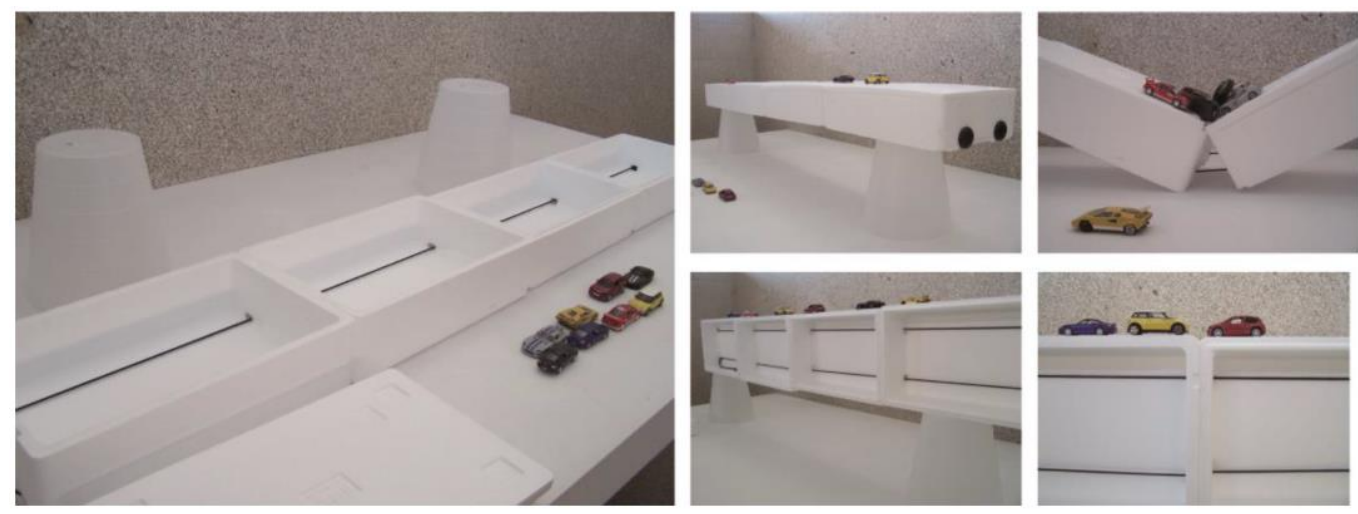

Figura 1. Taller explicativo de la construcción de puentes a partir de dovelas y técnicas de hormigón postesado dentro de la exposición Fisac HuesOs Varios. Museo Patio Herreriano. Valladolid (2008)

Fuente: Recuperado de https://www.youtube.com/watch?v=RkOwbsa33EY.

Superada esta fase inicial comenzaría la investigación postdoctoral, para ello se decide establecer una metodología de acción y crear un material propio de apoyo que terminaría por ser el gran referente del trabajo, la parte más visual. Un sistema constructivo basado en bloques con siete formas todos de igual espesor y proporcionales entre sí de modo que permitan múltiples aparejos y combinaciones. Se diseñó un modo de unión que permita compresiones y tracciones a través de unas geometrías propias de la ebanistería como son las colas de milano y se apostó por dar continuidad al EPS como material, por sus cualidades de ligereza, economía y por tratarse de un material inocuo apto incluso para un uso alimentario.

Las geometrías elegidas se estudiaron para permitir cierto grado de figuración en las construcciones, esto se logra fundamentalmente gracias a las tres piezas curvas. De modo paralelo se tramita la patente con fines de autoprotección pues parecía razonable que el invento ya existiera y pudiera generar algún problema de derechos finalmente no ha surgido problema alguno en ese sentido ${ }^{3}$.

${ }^{3}$ Sistema Lupo está protegido bajo la patente Nacional 200902060 Juguete de construcción desmontable a partir de bloques ligeros de gran tamaño y procedimiento para su fabricación. Parte de sus versiones están en abierto bajo licencias creative commons y algunas aplicaciones como lupo virtual es descargable libremente desde la web www.sistemalupo.com 


\section{Trabajar trasgrediendo los límites metodológicos}

Definido el material y los objetivos se realizan las primeras aproximaciones metodológicas. Esto supondrá un proceso de mejora y perfeccionamiento continuo que aún hoy continúa abierto. Es esta fase la que mejor define lo heterodoxo de la aproximación epistemológica.

Más allá de todas las cualidades y capacidades que posee la arquitectura como disciplina, están los intentos por generar momentos, experiencias que proporcionen las condiciones óptimas para el desarrollo personal y creativo. No se trata de generar dogmas pero tampoco admitir el todo vale, decía el filósofo Gustavo Bueno que pensar es pensar contra alguien, y tal vez algo de esto existe también en la educación, cuando se plantea una metodología no quiere decirse que sea la única posibilidad pero evidentemente se niega alguna.

Sistema Lupo no ha tratado de negar abiertamente ninguna metodología ni estrategia pero si se ha alineado con los métodos activos, experimentales, con el trabajo en equipo, con el learning by doing (Dewey, 1907), con la investigación como arma educativa....Esto deriva en una serie de influencias cruzadas que hacen difícil circunscribir el proyecto a una única línea de pensamiento. En ocasiones las referencias son incluso contradictorias. Se estudian las comunidades y también la fuerza del individualismo como arma de desarrollo de las sociedades al más estilo objetivista de Ayn Rand (2005). Se apuesta en ocasiones por el denostado modelo de clase magistral, se han utilizado métodos tan antiguos como los bloques de construcción y materiales ancestrales como la madera sin tratar o el barro pero eso no ha impedido desarrollar aplicaciones en soporte digital, ni el apoyo en aplicaciones web, en películas o en dibujos animados, prácticamente todos los medios son válidos o al menos útiles.

Se han estudiado los métodos educativos clásicos (Pestalozzi, 2009) y también los "modernos" y de modo crítico se advierten sus virtudes y tanto en unos como en otros una recurrente tendencia (salvo honrosas excepciones) a la creación de élites culturales y por supuesto económicas. Las bases educativas pertenecen a una tradición más que asentada. Pestalozzi, Piaget, Montessori, Vygotsky, Freire, Waldorf, Gadner, Malaguzzi... cada uno con sus peculiaridades han puesto en práctica, han escrito y han abierto caminos.

Cómo ejercer este magisterio con los condicionantes de nuestra época es el cometido de nuestra generación, como docentes, como padres, o simplemente como ciudadanos.

\section{3. ¿Por qué trabajar desde la arquitectura?}

Sistema Lupo propone una didáctica basada en el proyecto. Análisis teórico, aproximación experimental y conclusiones. Para experimentar este proceso mental enriquecido con la experiencia del trabajo colaborativo la metodología se apoya en el tradicional juego de bloques. A partir de esta herramienta se generan retos y desafíos al participante tratando de generar o mantener una motivación que sirva de estímulo al acto educativo. Esta fase incluye por supuesto el juego (Huizinga, 2012; Sutton-Smith, 1997).

Esta metodología de proyecto y ejecución es inherente a la tradicional manera con que la arquitectura ha sistematizado su educación ya sea de manera experimental o a través de 
modelos. Por eso resulta tan natural su aplicación en la educación y tal vez en parte por este motivo es cada vez mayor la presencia de equipos de arquitectos en procesos educativos (Encinas Hernández, 2015).

Trabajar por proyectos, design thinking, analizar para prototipar una idea en corto periodo de tiempo es algo que los estudiantes de arquitectura hacen desde primer curso.

Esto se traduce en hablar teóricamente sobre el tema a tratar, mostrar ejemplos, debatir y plantear un reto con un componente creativo.

Se trabaja con diferentes niveles de dificultad $\mathrm{y}$ acompañamiento desde fases completamente guiadas (siguiendo planos), o partes creativas donde el participante proyecta una solución al "problema/reto" planeado.

Y todo ello dentro de una dinámica que hoy llamaríamos "gamificada" donde el juego es el aglutinante de todas las partes, donde el deseado "aprender jugando" (Caillois, 2001) nace de manera casi natural. Todo ello es propio de la arquitectura y resulta atractivo para el participante, no se está inventando nada nuevo, cualquier escuela de arquitectura ha utilizado esta metodología (tal vez excluyendo el juego) desde antiguo.

A todo lo anteriormente comentado se suma el gran abanico de conocimientos que abarca la arquitectura desde la técnica al arte pasando por el planeamiento urbano y territorial o el diseño por citar los más reconocibles. Esto dota a la profesión de una especial predisposición teórica para la convivencia con otras disciplinas. Si bien la integración con otros campos no es algo especialmente fomentado en las escuelas de arquitectura la cruda realidad del mercado laboral hace patente estas potencialidades (figura 2).

\subsection{Del proyecto al método. Puesta en práctica (2008-2016)}

Sistema Lupo surge desde el ámbito museístico, y su aplicación como tal se desarrollará en la Fundación Luis Seoane de A Coruña, primero a través de talleres vinculados al contenido de las citadas exposiciones de arquitectura, diseño y tecnología y posteriormente en formato de cursos anuales que se denominan Nenoarquitectura.

El equipo cuenta con un perfil de monitores especializados que enriquecen la didáctica, salvo excepciones son arquitectos titulados con master en educación y licenciados en educación y en Bellas Artes con experiencia en didáctica de museos (figura 2).

En la primera edición (2008) se inician los talleres con un único grupo de 8-12 años de edad, el segundo y tercer año dos grupos de 6-9 años y 10-12 años y finalmente el cuarto año tres grupos de 4-5 años, 6-9 años y 10-12 años. Los talleres se distribuyen finalmente en 3 trimestres de 10 sesiones de dos horas y media de duración y con niños desde 4 a 12 años divididos en tres grupos; Tropieza (4-5), Empieza(6-9) y Despieza (1012), con grupos de 12-15 niños cada sábado en el centro con un monitor por grupo.

Fruto de la experiencia se modifican dinámicas y se crean protocolos algunos de los cuales siguen en permanente evolución. Se generan de modo progresivo más de 200 retos en formato ficha descargable y el material necesario se sistematiza en cajas de 65 bloques. Es una didáctica experiencial, los niños nunca se llevan nada físico a casa, terminado el taller la construcción se desmonta y vuelve a su caja haciéndose ellos partícipes de la recogida como parte del taller. La experiencia vivida les acompaña en su viaje de vuelta. Sólo al final de cada trimestre se llevan un pequeño cuaderno de obra en 
el que se reflejan los trabajos, apuntes, y reflexiones sobre el tema tratado en cada jornada.
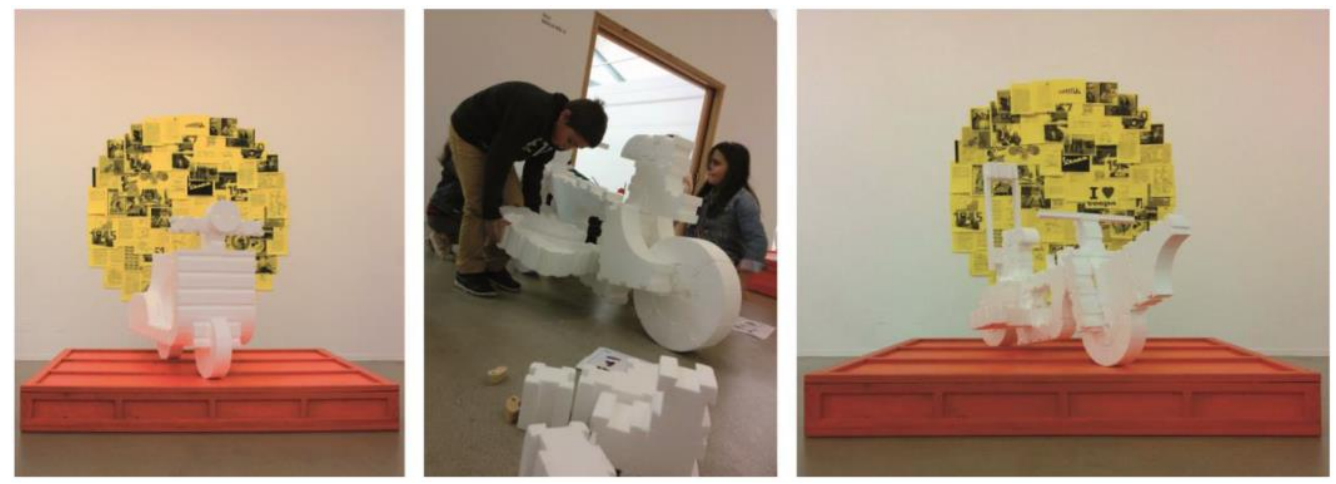

Figura 2. Taller sobre movilidad urbana. Secuencia metodológica de un taller sobre arte y diseño basado en la Vespa, icono del diseño industrial

Nota: La secuencia muestra la construcción guiada siguiendo planos de un modelo clásico de Vespa, el desmontaje y proyecto de un nuevo medio de transporte, obteniendo como resultado el prototipo Flash-gaviota un vehículo anfibio (tierra, mar y aire). Fuente: Recuperado de la Exposición Fundación Torrente Ballester (2016).

Como primeras conclusiones de los primeros cursos de Nenoarquitectura se observa:

- Que se genera una adhesión al proyecto por parte de niños y familias. Estas iniciativas en ámbitos no reglados no son viables si no existen matrículas. El centro mantiene y refuerza la presencia de los cursos creando el tercer grupo y abriendo Nenoarquitectura al contacto con los artistas y las obras de la programación anual lo que supone un enriquecimiento del proyecto.

- Los niños no pertenecen al mismo ámbito, proceden de diferentes barrios y colegios. Muy pocos proceden del entorno más inmediato del museo (ciudad vieja), casi todos se desplazan en vehículo particular cada sábado hasta los talleres, incluso hay casos de desplazamientos de más de $125 \mathrm{~km}$ lo cual para la geografía gallega es una distancia considerable. La sensación de no repetición, de enfrentarse al reto, a la investigación, al juego... convierten el taller en un reclamo para el niño.

El conocimiento de su ciudad y entorno inmediato es reducido aunque si son conocedores de los hitos patrimoniales.

1. Existe un público objetivo para este tipo de talleres que parte de la iniciativa familiar, un alto porcentaje de padres pertenecen al ámbito educativo o artístico.

2. La actividad constructiva requiere un proceso de concentración que no debe exceder los 30-40 minutos y debe alternarse con sesiones de debate $\mathrm{o}$ participación.

3. El uso de materiales monocromos favorece la visión conjunta de la construcción final. Se han hecho pruebas coloreando los bloques y aunque en un principio genera un efecto positivo la construcción genera un rechazo por parte del niño que no ocurre con el monocromo. Esto es aplicable a los bloques de gran escala. 
4. El trabajo con bloques de diferentes tamaños (manteniendo la relación de escala) favorece la aproximación individual o en pequeños grupos al reto previo a la fase de trabajo en grupo. La riqueza de participación e intercambio de ideas de grupos reducidos entre dos o tres integrantes es fundamental antes de encarar la gran construcción.

5. Se observa un buen funcionamiento de las sesiones grupales en las que los participantes asimilan unos roles diferentes a los que muestran en sus grupos originales. También la ruptura con la rutina al no seguir las sesiones casi nunca la misma estructura e incluso realizarla en diferentes espacios del museo.

A partir de esta primera experiencia el proyecto de investigación se convierte en método a raíz de la posibilidad de colaboración con otros centros y equipos por toda la geografía peninsular. Las estrategias serán diferentes, flexibles ${ }^{4}$ en función de los centros receptores del material (Habraken, 1999).

La cuestión es cómo transferir la experiencia del equipo a un tercero de modo ordenado y claro. Generalmente se opta por las sesiones de formación aunque esta fase dependerá en gran medida del centro receptor. En este punto entran en juego diferentes circunstancias. Por un lado se abre una línea ligada al "producto", la posibilidad de industrializar los bloques y también en parte la didáctica. Cómo colaborar con diferentes equipos educativos, qué aportar en cada caso. A los retos anteriormente citados se suma la estimulante tarea de entrar en el ámbito doméstico desde la industria y la educación. En un intento por democratizar la arquitectura y todos los valores que transmite y ante una situación de cambio tanto tecnológico como institucional y social, se decide apostar por un planteamiento flexible multiplataforma manteniendo las siete geometrías, extendiendo los bloques al mundo virtual, cambiando los bloques de tamaño, de material, experimentando con bloques comestibles, autoconstruibles, editables, transformables, etc... Y convertir el proyecto en algo útil para las diferentes realidades educativas que podemos encontrarnos y las que aún están por descubrir.

Esto ha llevado a colaborar con entidades muy diversas, con universidades públicas y privadas, con franquicias de las llamadas de "bajo costo", con administraciones, con fundaciones, con museos y también con colegios...Pasados 8 años y fruto de este trabajo más de 50.000 niños han participado de estas propuestas.

Las conclusiones parciales (figura 4) que se obtiene de esta fase pueden resumirse en:

- La implicación del docente, tallerista o responsable es parte fundamental del proceso. Como es bien sabido la figura del educador es clave en la mediación y aplicación de cualquier sistema. La aparición en momentos concretos de la figura del especialista o la figura invitada también es importante.

- Los colegios que trabajan por proyectos aceptan estas metodologías con mayor facilidad y generalmente como refuerzo de algunas sesiones o temáticas dentro del currículum general del curso.

\footnotetext{
${ }^{4}$ La flexibilización del método y su aplicación se basará en parte en las lógicas expuestas por Habraken (1999) sobre la creación de soportes base que sean manipulables y adaptables según las necesidades y abiertas a la participación del usuario.
} 

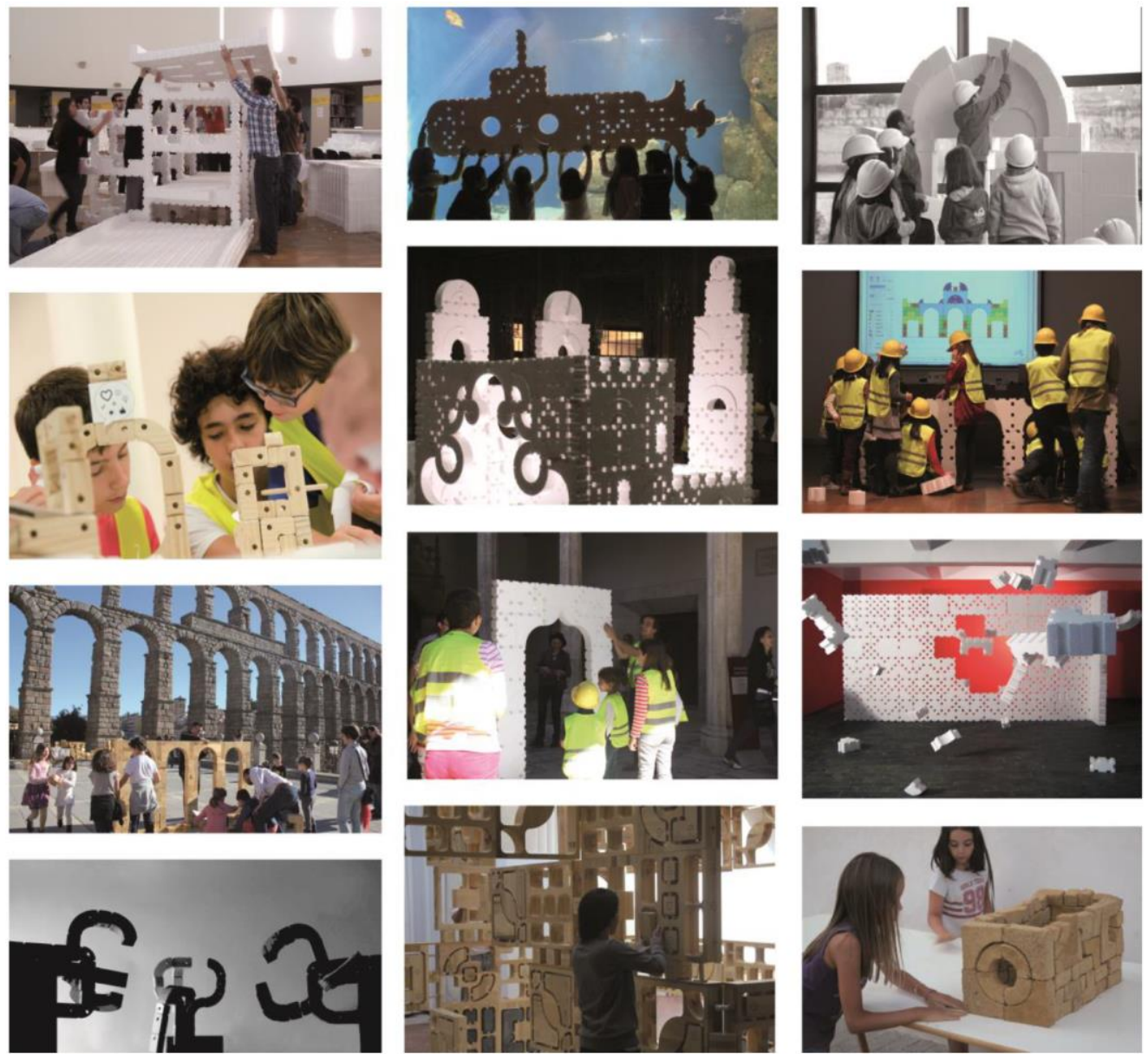

Figura 3. Imágenes de talleres realizados con diferentes materiales y en diferentes centros. De izquierda a derecha: patrimonio contemporáneo (Escuela de Arquitectura de

Donostia. Homenaje a Peña Ganchegui), Construcciones submarinas (Aquarium Finisterrae, A Coruña). patrimonio histórico (Zamora Románica), Dos en uno (CGAC y Museo do Pobo Galego, Santiago de Compostela), Semana de la Rehabilitación (Ateneo Comercial de Porto),Talleres de Nenoarquitectura (Fundación Luis Seoane), Proyecto Acueducto Mutante (Segovia), Calle Museo ( Museo Nacional de Escultura, Valladolid),

Frio Estudio del desastre (LABoral Centro de Arte, Gijón), Lo profundo es el aire( Museo Chillida Leku, Hernani), Yin yang Tulipwood (Casa de los Picos, Segovia), construcción con tierra (Fundación Cerezales, León)

Fuente: Elaboración propia.

- En aquellos centros más impermeables a recibir una metodología integrada en el curriculum, la aplicación de Sistema Lupo se circunscribe al área de conocimiento o curso del profesor implicado o al devaluado mundo de las actividades extraescolares.

- Los ciclos más receptivos para estos cursos son los de educación infantil y primaria.

- Los museos y centros cívicos vinculan generalmente su uso a la arquitectura propiamente dicha, en el caso de centros de arte contemporáneo también al autor. (ver proyecto MIESe+). Sin embargo se 
han desarrollado aplicaciones en campos completamente alejados de la arquitectura como el coaching, la improvisación, o la toma de decisión en fatiga dentro del ámbito deportivo...

- La ficha/reto que constituye la parte guiada de un taller es utilizada fundamentalmente como medio de acercamiento al juego, los códigos de color y la sistematización de las fichas ayudan tanto al participante como al monitor y son demandadas fundamentalmente cuando el monitor no es arquitecto.

- Las posibilidades de aparejo y sus geometrías hacen que el sistema se adapte a múltiples formas, la posibilidad de construir los iconos o símbolos de cada localidad o barrio aumenta las sinergias con la comunidad local. Todas estas creaciones generalmente terminan en un gran dossier del que todos pueden abastecerse fomentando el efecto red. La catedral de Oporto termina por ser una catedral medieval en el dossier general que puede ser utilizada en Burgos dentro de una didáctica sobre arquitectura medieval, lo mismo en las murallas de Lugo o los acueductos de Tarragona o Segovia, por no hablar de las pirámides que viajan de Egipto a México y de las clases de historia a las de geometría.

- Las redes sociales ayudan en la recogida del feedback, parte de los retos propuestos proceden del uso creativo de los propios niños y los diferentes centros retroalimentan con sus propuestas la didáctica.

Al tiempo que el equipo avanza y se pulen las metodologías han ido apareciendo otras circunstancias que de un modo u otro afectan a la toma de decisiones. Fundamentalmente temas relacionados con la producción de materiales, con la distribución, con los sponsors y con la autogestión económica del proyecto.

Cada vez que se ha tomado una decisión vinculante y estructural podemos decir se ha hecho siguiendo una ética de producción evitando generar precariedad en un campo ya de por sí precarizado hasta extremos inconcebibles.

Los productos están controlados en toda la cadena de producción y se fabrican desde la Península Ibérica a través de fabricantes locales tratando de generar beneficios en las comunidades de origen. Se siguen medios pseudoartesanales incluso cuando la fabricación se sistematiza y todo proyecto que pasa a nivel de producto es certificado por los laboratorios correspondientes. En este sentido se entiende como fundamental el texto con los consejos para el diseño del juguete (Munari, 2013) en el que se enuncia en varios de sus puntos la necesidad de colaboración con profesionales expertos en procesos industriales, en psicología, en pedagogía y en didáctica durante el proceso de diseño del juguete. Desde Sistema Lupo se trabaja en la ampliación y adaptación de este listado, introduciendo al niño en el proceso de diseño y fabricación de las propias piezas, colaborando con artistas en los talleres vinculados a los museos o profesionalizando la etapa posterior del juego y el taller en la que siempre existe contenido didáctico vinculado a la actividad constructiva. Se entiende el trabajo de una forma profesional en la que por supuesto nadie trabaja sin estar asegurado, son comentarios inocentes pero que cabe resaltar pues la falta de profesionalidad en el sector es más que preocupante y el abuso del apoyo en estudiantes no remunerados o el voluntariado es una constante 

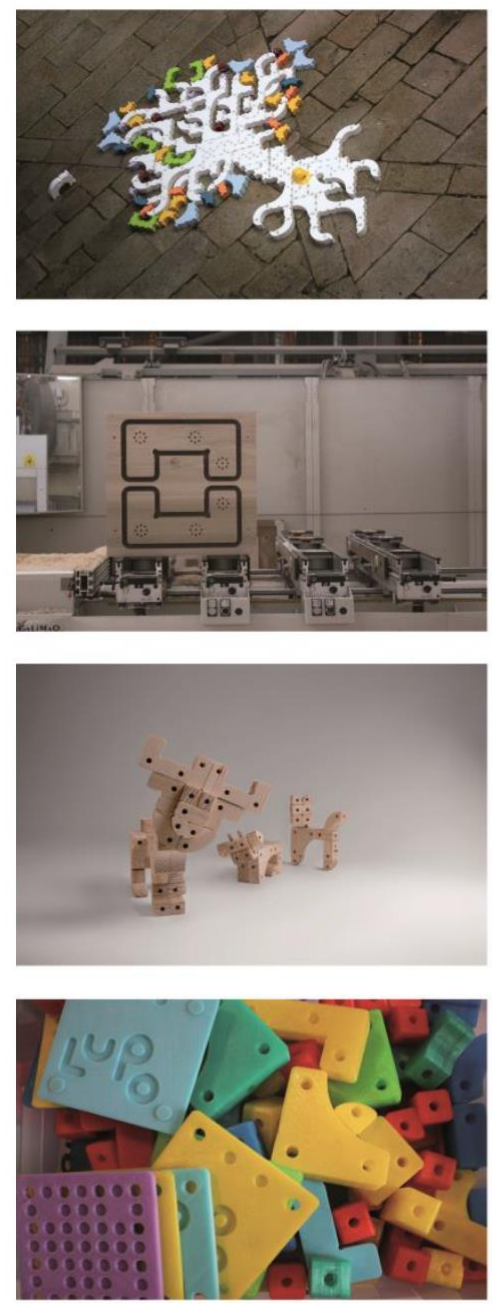
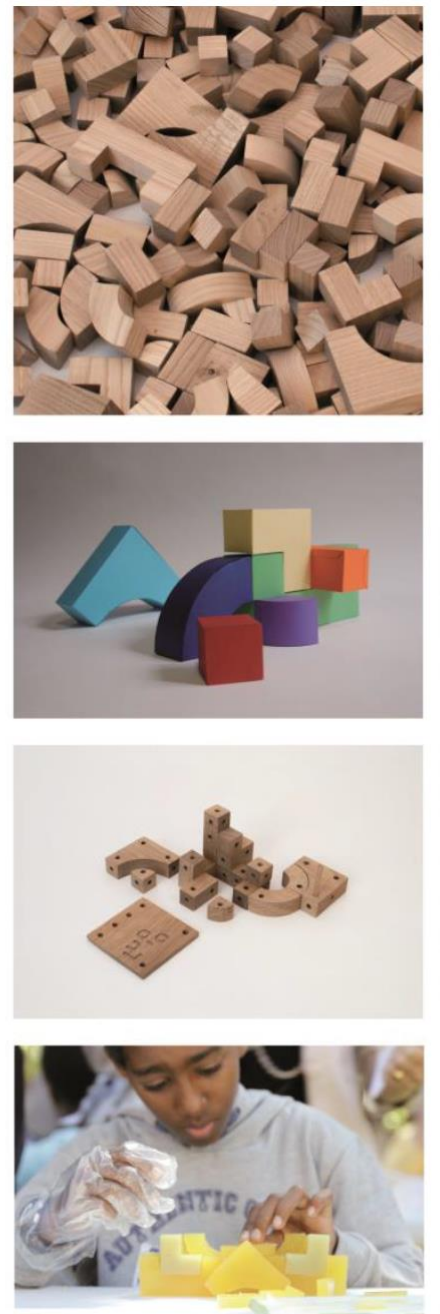
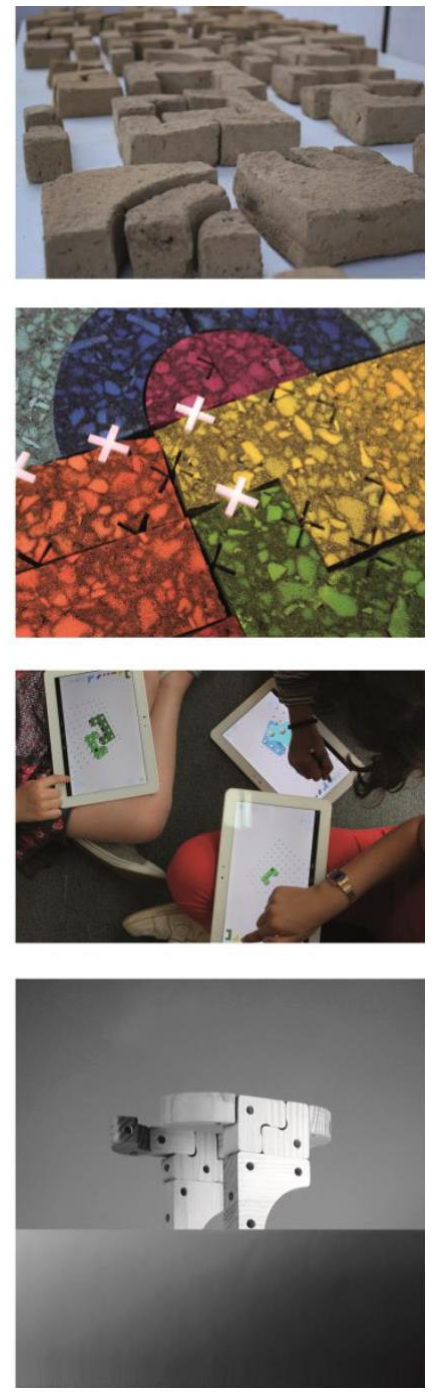

Figura 4. Imágenes de diferentes productos algunos de ellos experimentales, donde se trabaja con las posibilidades de materiales y técnicas de fabricación diferentes, algunas de las cuales incluyen al participante como generador del producto. Super Lupo, Eco Lupo, Lupo Plot, Lupo virtual, Lupo ñam...

Fuente: Elaboración propia.

Con ánimo de que este texto sirva de ayuda tanto a quienes se dedican al diseño de herramientas o métodos educativos como para aquellos que estén involucrados en la comunidad educativa o simplemente en el desarrollo de productos para este ámbito, el resto del artículo constituye un listado analítico de experiencias didácticas que por un lado han servido de referencia y por otro lado han enriquecido al equipo asentando el método. Por este motivo esta parte está dedicada tanto a las conclusiones extraídas de la puesta en práctica del proyecto referidas al usuario final como a las experiencias que nos han enriquecido al equipo en este viaje desde la arquitectura a la educación.

...Es bien sabido que cada uno se mueve como si tuviese dentro una (o más de una) teoría. Esto también es verdad para los educadores: sean conscientes o no, ellos piensan y actúan siguiendo teorías personales que deducen de historias que, en ocasiones, son difíciles de reconocer. El problema es cómo asociar esa teoría con la 
educación de los niños, con las prácticas relacionales y con las normas del trabajo...

(Malaguzzi, 2011, p. 83)

\subsection{La universalidad de la baja tecnología y el anonimato. Un caso práctico: el ayatori}

Ayatori, juego de hilos, cat's craddel, sokatxo, juego de la pita, figuras de cuerda... Diferentes nombres desde diferentes lugares nos remiten a este juego. La potencia del juego deriva de la simplicidad del material necesario, una simple cuerda atada en sus extremos y de la técnica que admite diferentes grados de dificultad y posibilidades. A esto se suma la dificultad añadida de no poder ser jugado por un único jugador sino que la dinámica es por parejas (figura 5).
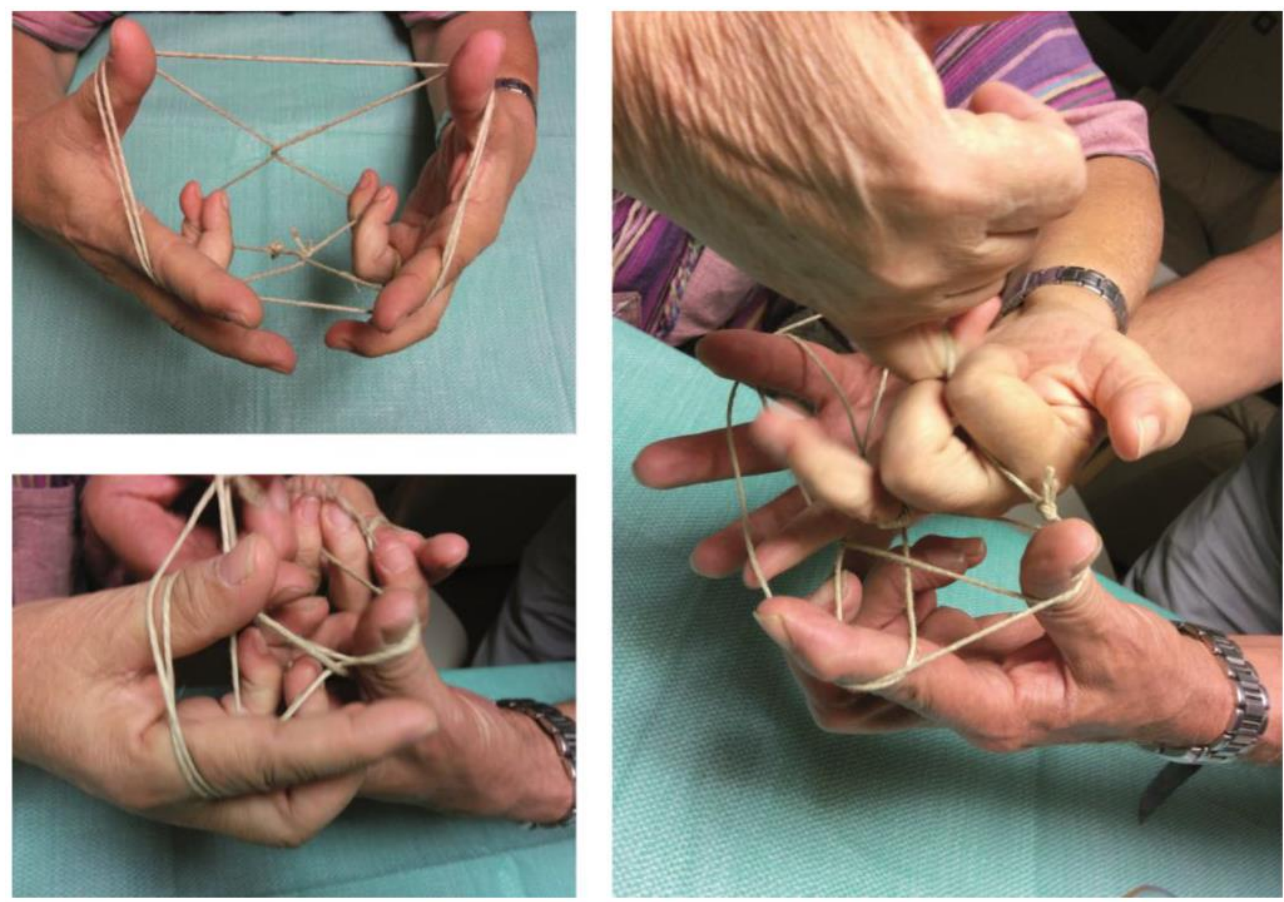

Figura 5. El ayatori no entiende de edad, pareja de primos rememorando las geometrías de los hilos sesenta años después

Fuente: Elaboración propia.

Las cuerdas pasan de estructuras planas a tridimensionales a través de la posición de los apoyos en dedos extremos. Estos juegos generan destrezas manuales, estimulan la psicomotricidad fina, y también la visión espacial a través de las estructuras bi o tridimensionales obtenidas. Destacan por la simplicidad de medios y sus múltiples posibilidades. No suelen acompañarse de libros de instrucciones ni manuales y sin embargo sus posibilidades han pasado de generación en generación a través de la tradición oral y visual. Por supuesto su origen es desconocido y se hunde en el principio de la historia y sin embargo aún hoy funciona.

Estas propiedades básicas constituyen un referente en Sistema Lupo, se ha tratado desde el principio de generar estructuras con un grado de complejidad tal que no puedan ser acometidas por un único participante forzando la colaboración desde la propuesta del reto. Por otro lado también se utilizan las técnicas de la simetría o doble simetría y los grupos para favorecer la creación de sub equipos, parejas o tríos dentro del equipo 
general de montaje. Todo ello dentro de una lógica de trabajo en equipo. El reto del fórmula uno que figura en la documentación de la patente pretende reproducir el espíritu de la escudería con sub equipos haciendo ruedas, chasis y motor más que la gloria del piloto como héroe solitario.

\subsection{La repetición, las variantes y el infinito}

Cualquier proyecto es una oportunidad, cualquier detalle puede ser un buen momento para desarrollar tu yo creativo así lo demuestran casos como el de la piedra laberíntica de Silo. En la asturiana localidad de Santianes de Pravia, se encuentra una joya del arte pre-románico o arte Asturiano, la iglesia de Santianes es la más antigua dentro de este estilo y abre un nuevo modo de entender la arquitectura medieval en Europa. Son numerosas las influencias que este estilo genera en Lupo, el uso del módulo a partir del pie carolingio o sus variantes geométricas y volumétricas. Sin embargo en este caso destacamos una pequeña placa conmemorativa que ha generado gran cantidad de literatura, una enigmática piedra fruto de la habilidad y genialidad de algún cantero de la época (s. IX). La conocida como piedra laberíntica de Silo es una caliza donde han sido grabadas una serie de letras ordenadas según una trama de 19 columnas y 15 filas que reproducen la frase Silo princeps fecit (lo hizo el príncipe Silo) el juego que plantea, consiste en comenzar la lectura desde la $\mathrm{S}$ central y tratar de leer con la única condición de que la lectura se haga hacia el exterior de la trama pudiendo girar el sentido de la lectura en cualquier punto. Diferentes estudios han tratado de averiguar las múltiples combinatorias a que da lugar este simple juego (figura 6).

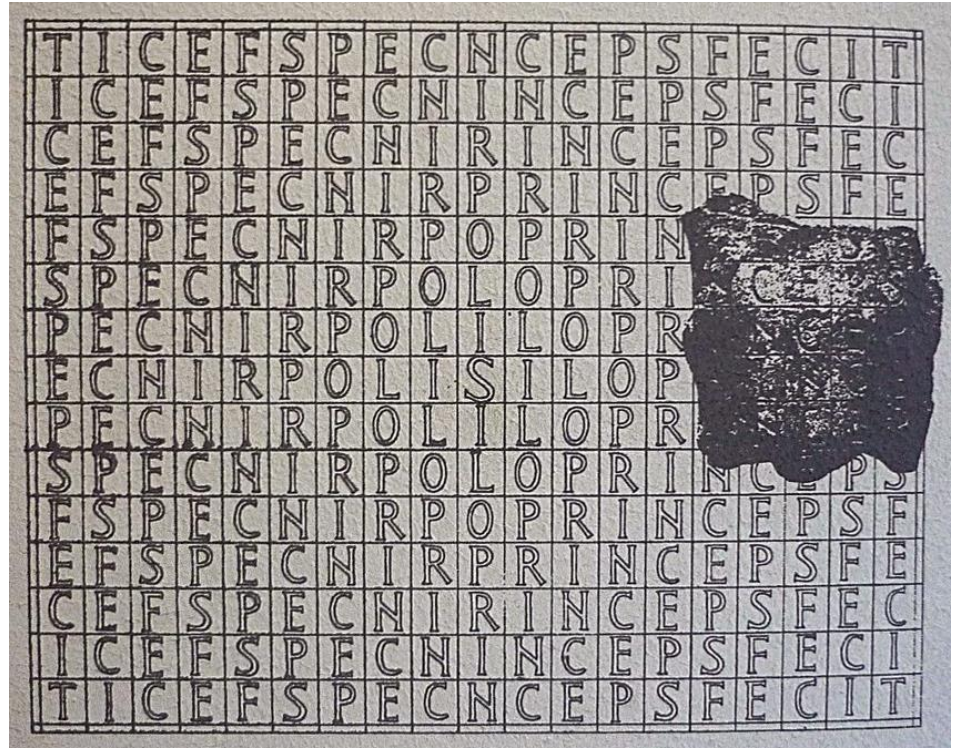

Figura 6. Reconstrucción de la piedra laberíntica original a partir del fragmento encontrado en la restauración de 1975 según F. Diego Santos. Su disposición permitía múltiples lecturas de la frase básica, a partir de una $\mathrm{S}$ central girando en cualquier letra siempre hacia el exterior: Silo princeps fecit Fuente: Elaboración propia.

Un acto común como es la firma de la obra puede terminar por convertirse en un auténtico acto artístico e intelectual. Con su realización el cantero demostró mucho más que sus habilidades manuales en el trabajo de la piedra. 


\subsection{Esther Ferrer y la búsqueda del infinito}

La dicotomía entre el individuo y la sociedad, lo personal y lo comunitario, o entre la unidad y el infinito, ha influido en la obra de diferentes artistas, en este sentido la obra de Esther Ferrer ha sido un referente. Su obra es íntima completamente personal y sin embargo sus aportaciones en el mundo del arte son estimulantes y dan muestra de esa importancia del individuo en la sociedad (figura 7).

Unido a esta obsesión por agotar un recorrido investigador en el caso de Ferrer es destacable también el formato de performance en que ha desarrollado gran parte de su obra, lo que supone un juego abierto a los acontecimientos, un proceso. Cuando Ferrer interactúa con su público, plantea un juego, y en ese sentido se expone a perder el control absoluto del resultado. El hecho de utilizar un género como la performance evidencia aún más ese peligro del accidente, de la pérdida de control. El concepto de abrir un campo de juego con ciertas normas pero sin un claro final es sin duda el principio fundamental de un buen taller creativo.
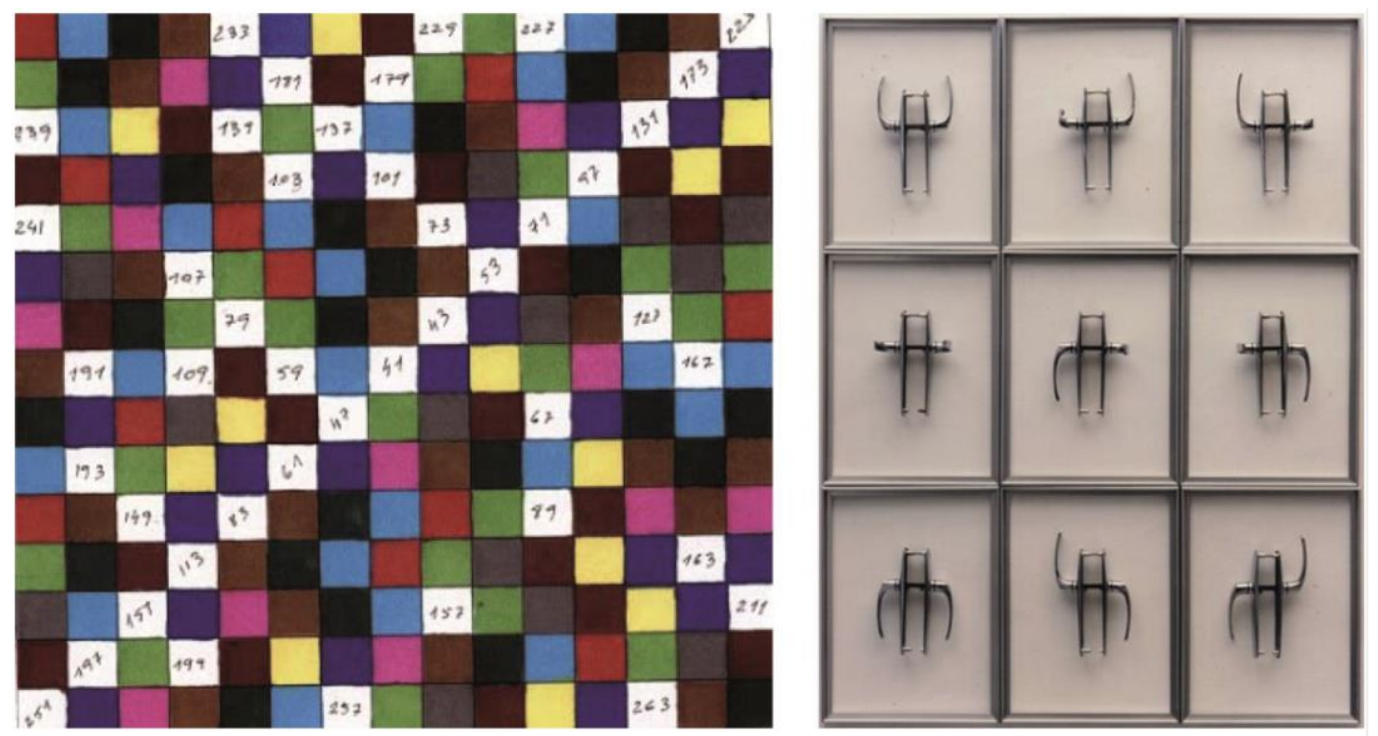

Figura 7. Izquierda: Espiral 5. Ullan. Proyecto para obra. Serie: números primos. Derecha: Marcos y manillas. 96x78x12 cms. Pieza dentro de la exposición: En el marco del arte matemático (Permutaciones)

Fuente: Elaboración propia.

Tanto el anonimato comentado en el punto anterior como el extremo personalismo del autor de una obra han resultado atractivos. Y el trabajo continuado durante años sobre las posibilidades de los bloques no deja de mantener este pulso obsesivo para intentar obtener hasta la última gota del limón. La repetición es además un hándicap y un estímulo, ser capaces de generar dinámicas que no agoten al equipo ni al participante. Crear experiencias site-specific es una estrategia pero crear dinámicas para los mismos niños durante muchas sesiones es ya otra historia y bien los saben los profesores que cada día intentan mantener la motivación durante un curso completo. Por este motivo Sistema Lupo se centra en servir de complemento a los educadores y dotar de experiencias que entren de manera natural casi sin forzar en el los objetivos del curriculum. No pretende aprovechar los evidentes beneficios a corto plazo del paracaidista que llega un día al aula y se va, lo que interesa es introducir ingredientes en 
la herramienta para hacerla útil durante varias sesiones de manera casi infinita. La complicidad del docente o mediador es por tanto fundamental.

\subsection{Luis Seoane y el laboratorio de formas}

La Fundación Luis Seoane ha sido la cuna de Sistema Lupo y su espíritu ha impregnado el mismo. Luis Seoane fue un artista polifacético que trabajó en el campo de la pintura, el muralismo, pero también el diseño gráfico, también trabajó en el campo editorial o en la radio y en colaboración con Isaac Díaz Pardo creó en 1963 el Laboratorio de Formas auténtico centro creativo donde investigación, arte y empresa se fusionan a través de un proyecto cultural e industrial 5 .

Desde el Laboratorio de Formas y desde las fábricas de O Castro y Sargadelos se genera un ambiente de investigación y producción donde seminarios, charlas, y conferencias darán paso a un proceso de industrialización de productos domésticos con calidad artística y componentes patrimoniales y culturales. Los productos con que la marca Sargadelos inundó las viviendas durante años, están plagados de referencias culturales, sociales e históricas (figura 8).
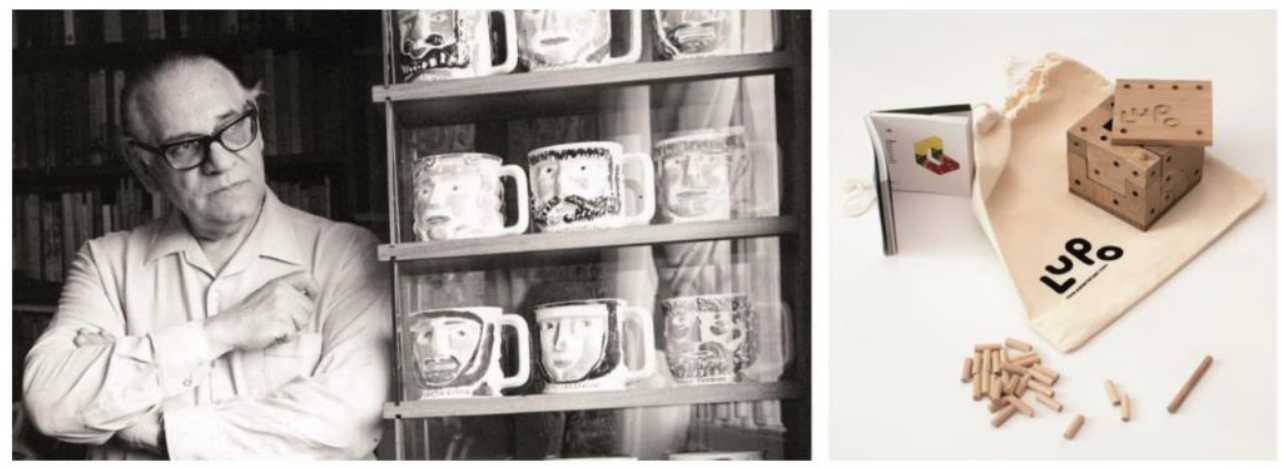

Figura 8. Izquierda: Luis Seoane posando con la colección de jarras-cabeza de personajes históricos de Sargadelos. Diseñadas por el propio Seoane durante los años 70, la colección estaba compuesta por 19 personajes relevantes de la historia de Galicia y 10 personajes de la historia de España en un claro intento de acercamiento de la cultura y de la historia a todos los hogares. Derecha: versión de Lupo Block, versión doméstica de 13 piezas en maderas frondosas Fuente: Elaboración propia.

Hoy en día ese espíritu de Luis Seoane se difunde a través de la fundación que lleva su nombre. Una texto fundamental para interpretar su figura y pensamiento es el titulado "acerca de la integración de las artes" (1962) escrito en el boletín de la Universidad de Buenos Aires donde el artista muestra su tesis en favor de una verdadera integración artística.

En ese sentido los talleres si bien utilizando la arquitectura con hilo conductor han sido permeables a cualquier experiencia artística y se ha tratado de complementar con

\footnotetext{
${ }^{5}$ El proyecto parte de la recuperación de las instalaciones de la empresa Sargadelos cuya famosa planta circular (1972) será realizada según los planos del arquitecto Andrés Fernández Albalat tercera pata de este tridente fundamental.
} 
artistas, diseñadores y artesanos aprovechando las sinergias propias del programa anual del centro. ${ }^{6}$

Desde el año 2008 se ha planteado un proyecto de divulgación en tres niveles que se retroalimenta. Bajo diferentes nombres se han desarrollado cursos anuales para adultos sobre investigación en arte y arquitectura, talleres para profesionales y talleres infantiles. Los talleres infantiles, la mencionada Nenoarquitectura ${ }^{7}$ ha asumido en parte la teoría procedente de los cursos para adultos, generalmente fruto de tesis doctorales y trabajos de investigación tanto dentro como fuera del ámbito universitario. El componente investigador ha sido un continuo desde el nacimiento de estos talleres tratando de mantener la coherencia y el rigor de los temas tratados. El equipo didáctico de Sistema Lupo ha sido el encargado de fagocitar esta información y hacerla digerible para las distintas edades y circunstancias.

\subsection{El juego debe ser limpio, la derrota (siempre parcial) forma parte del juego. Ramón LLull. Ars combinatoria}

El gran pensador mallorquín ha sido este año (2016) homenajeado al cumplirse los 700 años de su fallecimiento, la sucesión de actos han puesto nuevamente el foco sobre sus ideas, la exposición del CCCB La máquina de pensar, ha sido una gran muestra de la contundencia y vigencia en nuestros tiempos de un pensador del siglo XIV (figura 9).
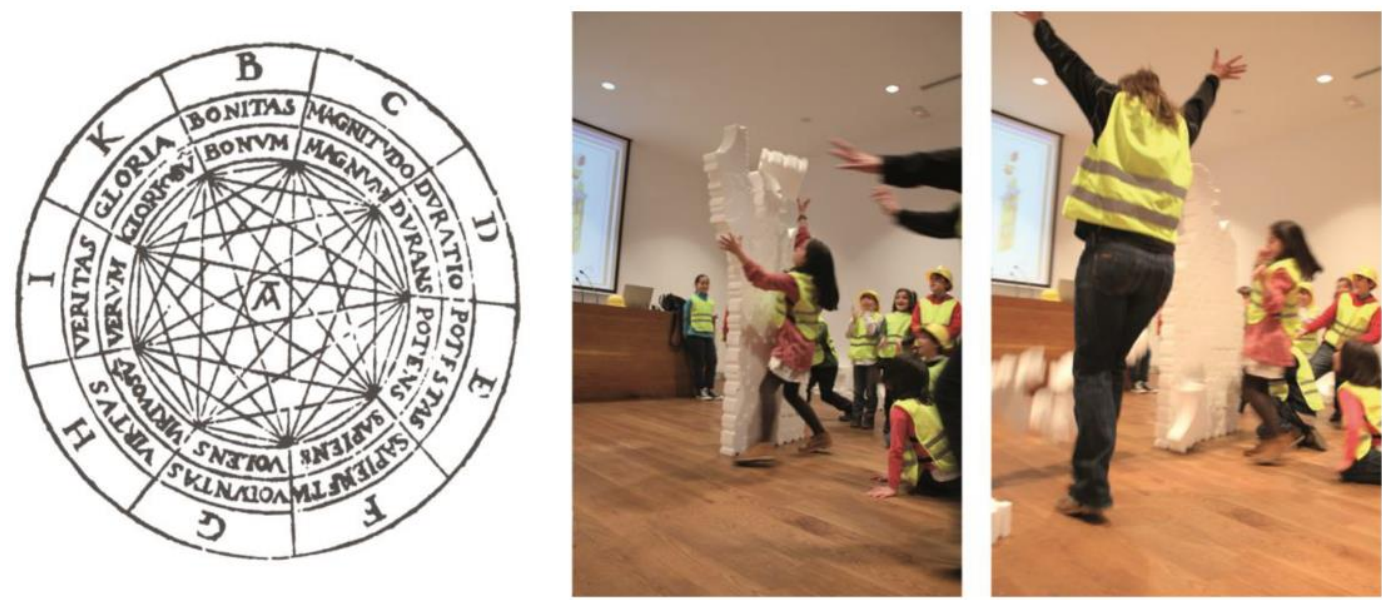

Figura 9. Izquierda: Ars Magna Generalis. Ramón Llull. 1275-1315.Centro y derecha: momentos cumbre previos a una demolición en un taller de Nenoarquitectura Fuente: Recuperado de Fundación Luis Seoane.

Lo que Llull llamó su Arte, es un método de razonamiento que deja a un lado los textos sagrados para centrarse en su análisis e interpretación. Método que representó a modo de juego con figuras redondas y triángulos y una seria de relaciones. A través de estos juegos dialécticos, el pensador intentaba convencer mediante argumentos al contrario.

\footnotetext{
${ }^{6}$ Proyecto Matrioska. Realizado en la Fundación Luis Seoane el año 2015 en colaboración con Idoia Cuesta. http://ferminblanco.com/web/?Page_id=2 172

${ }^{7}$ Nenoarquitectura. Ejemplo de taller realizado durante el curso en:

http://sistemalupo.ferminblanco.com/blog/2016/02/26/ciudades-sumergidas/
} 
En este caso entran en disputa las religiones. No se trataba de humillar a su oponente sino de convencer a través de razones que no pudieran ser alteradas (Joan Santanach).

La imagen tradicional de Llull como pensador abierto al diálogo ha sido últimamente discutida desde la crítica y hay quien considera que en realidad el juego, en apariencia abierto, está trucado y sólo conduce a un resultado, a un único vencedor. En este caso al cristianismo como religión verdadera frente al judaísmo o a al pensamiento musulmán.

En el juego de la filosofía, se establece el debate como campo de juego donde debe haber un vencedor y un vencido y esto se hace a través de unas tesis que deben ser demostradas a través del razonamiento. Dependerá de las habilidades de los contendientes y su capacidad de raciocinio y dialéctica el resultado final.

En el caso que nos ocupa el concepto coge fuerza y es al tiempo punto de discordia. La competitividad, innata o cultural, hace que el niño tienda a competir por ejemplo creando torres más y más altas, haciéndolas más rápido o más espectaculares. Las catedrales medievales, las torres urbanas o los palacios y sus jardines barrocos también participaron de esta competitividad del mundo adulto sin embargo sus valores como metodología educativa son negados sistemáticamente y conocemos sus perversos efectos. Incluso cuando sirven para reforzar lazos comunitarios siempre lo hacen para enfrentarnos a otras comunidades. El carácter competitivo en una dinámica de equipo debe ser siempre canalizado en favor de de auto-superación (personal o de grupo). Perder o fracasar en el intento tampoco debe ser vivido como un drama, las demoliciones y colapsos que a menudo acompañan a los talleres se viven dentro de una normalidad relativa que debe ayudarnos a levantarnos nuevamente. El fracaso es siempre parcial y está incluido en el proceso del hacer, la gestión de este sentimiento de frustración inicial también necesita ser entrenado.

\subsection{La importancia del manual. Actividades guiadas y libres. Frío estudio del desastre. Los carpinteros}

En 2010 Sistema Lupo fue invitado por Laboral Centro de Arte (Gijón) para realizar una didáctica basada en la exposición Pasajes. Viajes por el híper-espacio. La exposición mostraba una selección de obras de la colección Thyssen- Bornemisza Art y entre ellas se encontraba una magnífica instalación del colectivo cubano Los Carpinteros (figura 10 y figura 11)

La obra Frío estudio del desastre sirvió de hilo conductor a la didáctica, se propuso un taller con personas mayores, principalmente mujeres implicadas en asociaciones vecinales de diferentes barrios de la ciudad. Posteriormente se desarrolló un programa didáctico infantil para aplicar a través del equipo propio del centro durante el periodo de exposición. ${ }^{8}$

Aún siendo ésta una obra impactante y expresiva, el equipo se vio completamente seducido por su formato. La obra no existe en depósito alguno, lo que la fundación Thyssen compra y almacena son unas instrucciones de montaje. Es decir la obra consiste en una receta que incluye los "ingredientes" necesarios y el modo de combinarlos, incluyendo en este caso los refuerzos propios en la parte superior del boquete, bien es sabido que es más fácil realizar un muro completo que una apertura en el mismo, y qué

\footnotetext{
${ }^{8}$ Más información sobre el proyecto en: http://sistemalupo.ferminblanco.com/blog/2015/04/06/lupo-los-carpinteros-2/
} 
duda cabe que la dificultad aumenta exponencialmente si lo que deseamos es construir una demolición.
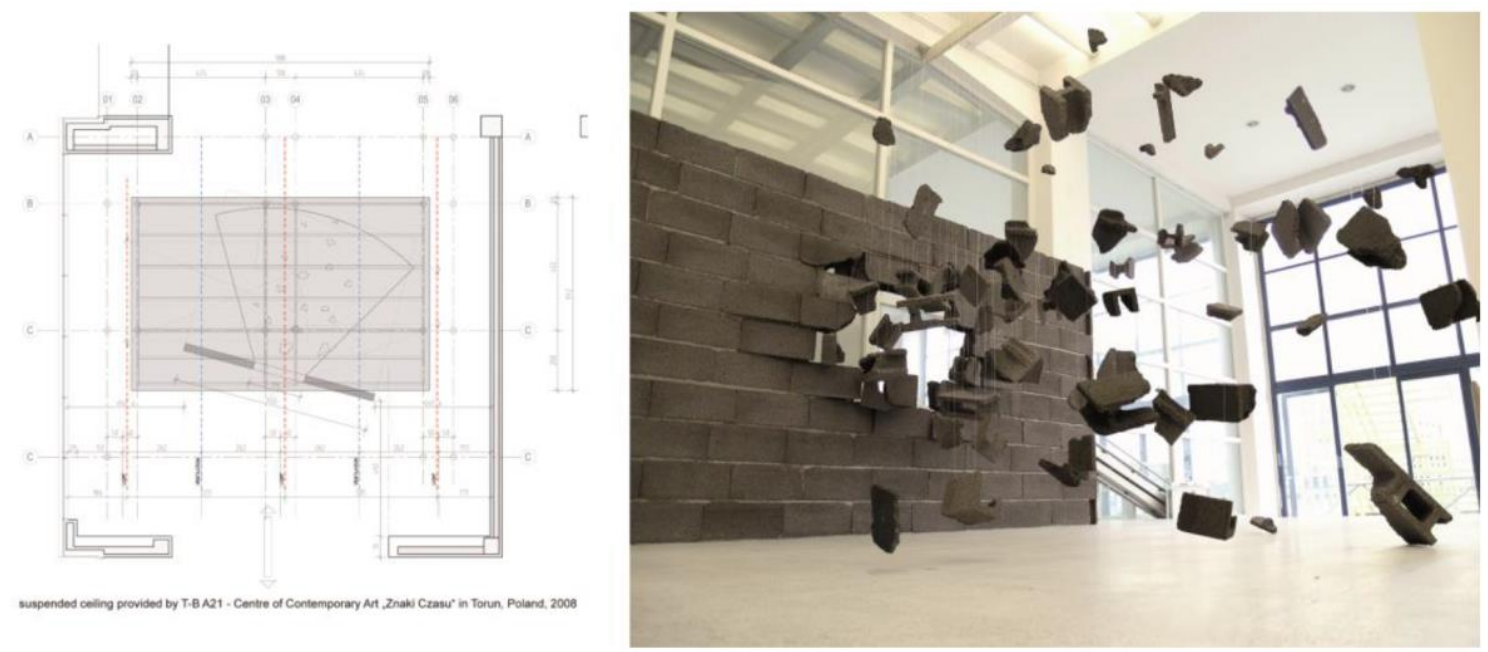

Figura 10. Frío estudio del desastre. Los Carpinteros. Laboral centro de arte y creación industrial. Gijón. 2010. Instrucciones de montaje y ejemplo de obra terminada Fuente: Elaboración propia.
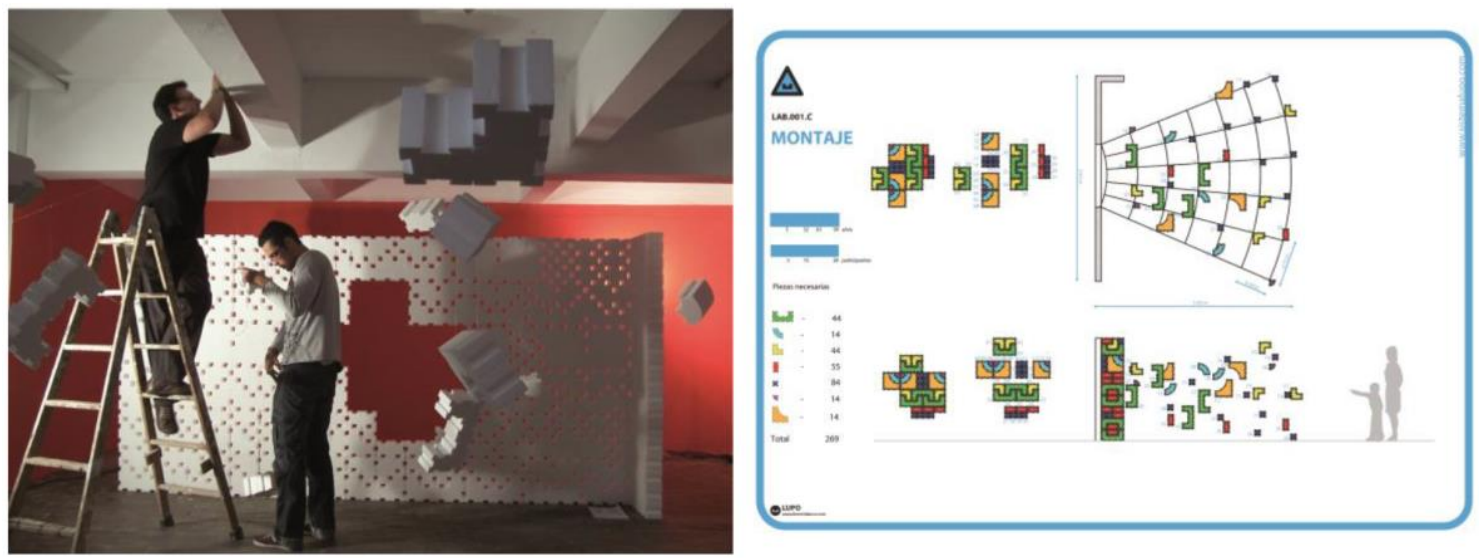

Figura 11. El taller didáctico se realiza en colaboración con una asociación de mayores que serán los encargados del montaje expositivo. Se explica la vulnerabilidad de las estructuras arquitectónicas a través del estudio del muro y la relación espacio-tiempo en la instalación artística

Fuente: Elaboración propia.

La importancia del manual es algo que se ha ido poniendo en valor progresivamente a través de los investigadores, en este sentido los estudios de Juan Bordes (2007) sobre los juguetes de construcción a lo largo de la historia, aclaran la importancia del manual que tradicionalmente acompaña al juguete de bloques, los libros del tutor auténticos tratados de geometría, aritmética, cristalografía o gramática son la clave en ocasiones para valorar la fuerza educativa del juguete.

El trabajo sobre el libro/manual de apoyo es una constante que ocupa gran parte de los esfuerzos actuales del equipo de Sistema Lupo. Más aún en un momento como el actual, en que el libro de texto está satanizado, en parte con gran razón, en virtud de una 
industria muy dirigida y gestionada generalmente desde órdenes religiosas que, aprovechando sus mercados internos de redes de centros, se han extendido incluso a la educación pública mercantilizando el instrumento educativo, en clara connivencia con las administraciones implicadas.

\subsection{El empoderamiento de lo infantil. Sandra Cinto. Sao Paulo}

Sandra Cinto es una artista brasileña con sede en Sao Paulo caracterizada por obras que aúnan el carácter sensitivo, reflexivo y comunitario. En sus murales trabaja la gran escala a través de la aparente fragilidad de la línea para generar efectos sorprendentes a través de la repetición. En ocasiones estas líneas son realizadas con la colaboración de comunidades que aportan sus esfuerzos dentro de un proyecto común (figura 12).
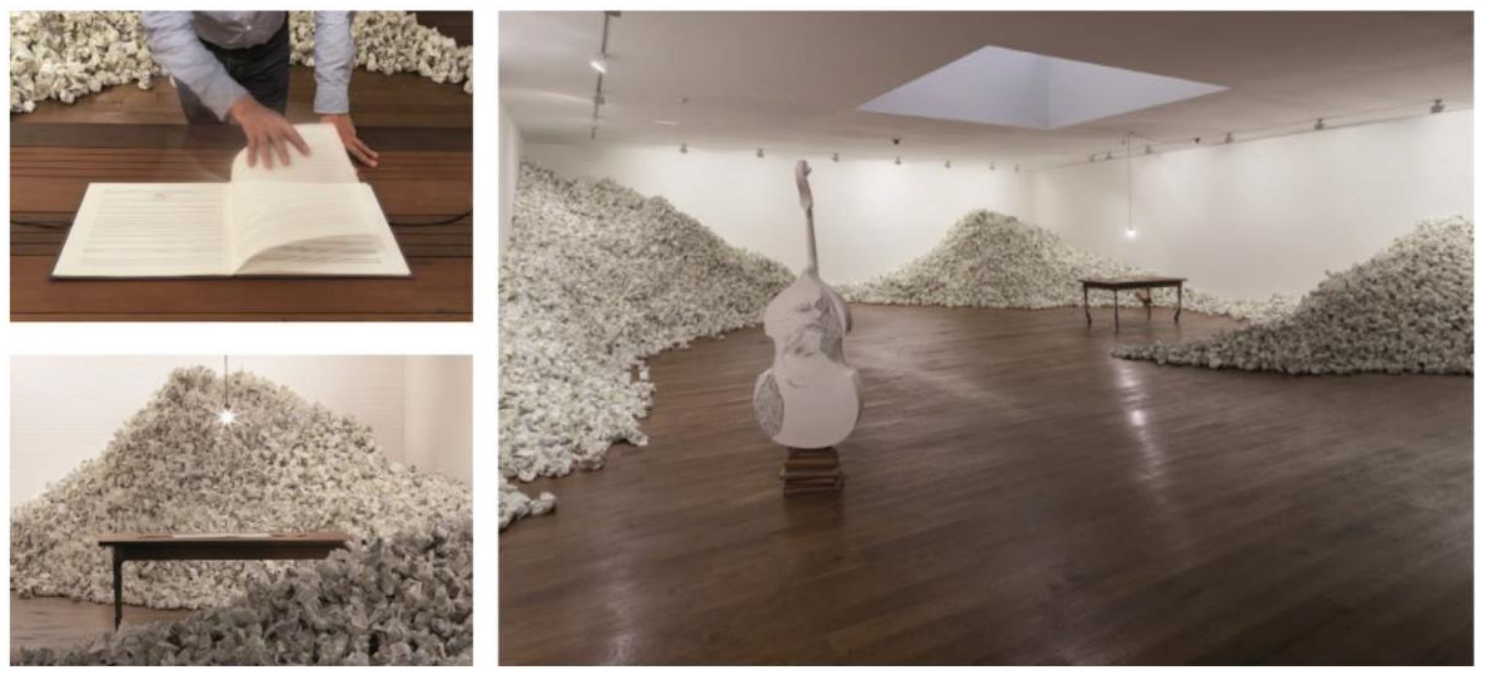

Figura 12. Sandra Cinto. En Silencio

Fuente: Recuperado de Fundación Luis Seoane. A Coruña.

"En Silencio" es una instalación site-specific en la que recrea un gabinete de trabajo, un lugar del que el creador está ausente pero en el que se evoca la dureza y vacuidad del acto creativo mediante la presencia de una mesa frente a la que la artista sitúa un violonchelo sobre una pila de libros, dominados ambos elementos por una montaña de papel, restos de partituras inacabadas que nos remiten al sufrimiento del esfuerzo repetitivo del artista.

A partir de esta obra se propone el proyecto "Tetraktys, el aparente silencio de los planetas”, ese misterio que ya desde la antigüedad clásica, ocupó a los pensadores. El filósofo clásico tenía un compromiso con la investigación y la sociedad envidiable. En él recaía la tremenda responsabilidad de dar respuestas a los grandes enigmas que la comunidad reclama. Serán estas primeras hipótesis y teorías las que traten de acercarnos a un entendimiento global del mundo en todas sus escalas, desde la estructura de la hoja de un árbol hasta el orden cósmico. En este emocionante momento de la historia, la música, la geometría y consecuentemente la proporción tomaron especial protagonismo. La música de los cuerpos celestes, su relación con el monocordio o la geometría presidieron los escritos y pensamientos de la época y serán los protagonistas de la didáctica propuesta. 
El proyecto se realiza coincidiendo con la clausura de la exposición y también con el final de uno de los trimestres de Nenoarquitectura, en estas jornadas los grupos y las familias se unen entremezclando las edades e intercambiando roles.

Se trata de crear una nueva exposición aprovechando los momentos de vacío entre el desmontaje y montaje (figura 13). Estos momentos son siempre muy sugerentes en un centro de arte y los niños se sienten dueños del espacio. La propuesta consiste en aprovechar el vacío de la sala para crear una nueva exposición y abrirla al público durante un par de semanas. El material del montaje se obtiene reciclando el material de la exposición original (cajas de cartón y bolas de papel arrugadas). Este efecto de empoderamiento del niño, de visibilidad, genera un efecto muy positivo en su valoración del trabajo. Los talleres infantiles abandonan su común marginalidad y el centro les da el protagonismo del que raras veces gozan, la complicidad con el artista es fundamental para el buen desarrollo de la actividad y el resultado final puede llegar incluso a complementar la obra ${ }^{9}$.
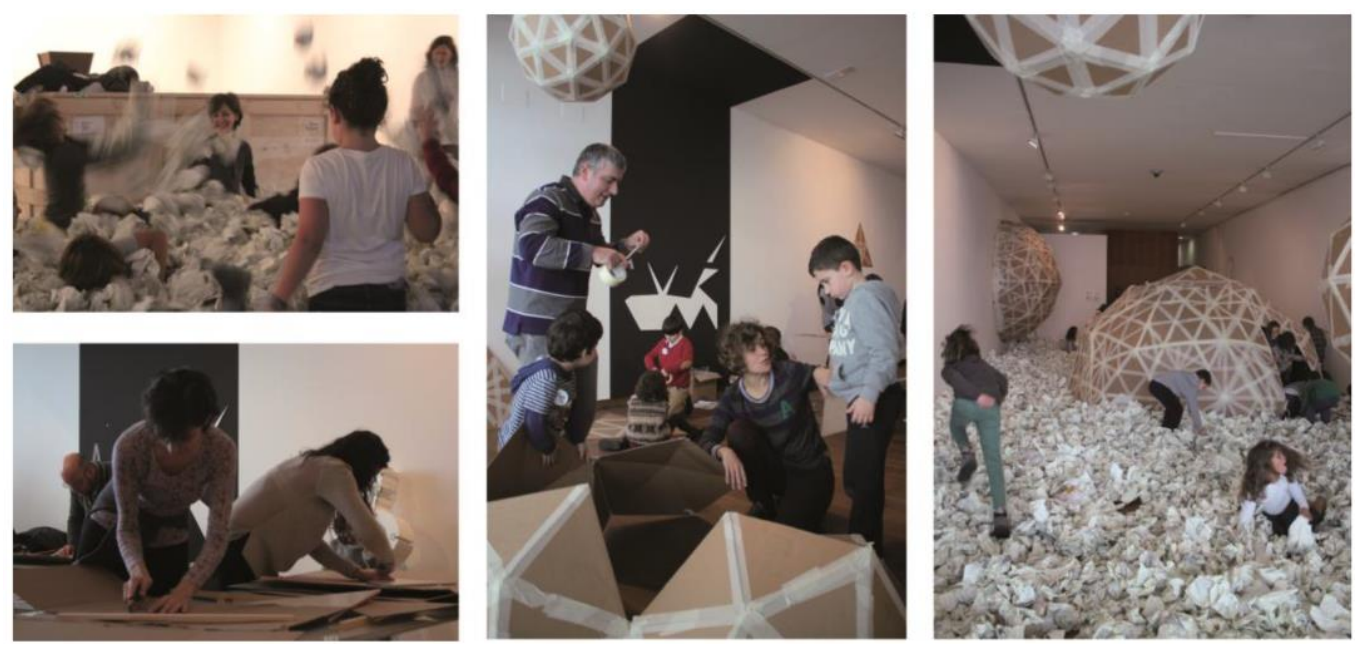

Figura 13. Imágenes del taller familiar Tetraktys realizado en la Fundación Luis Seoane y realizado en unas condiciones totales de complicidad y cooperación con la artista

Fuente: Elaboración propia.

\subsection{El espacio educa. Antonio Flórez. El arquitecto de las escuelas}

Antonio Flórez es uno de esos arquitectos cuya fama no alcanza grandes niveles de popularidad. Su obra sin embargo es rica y ha dejado una huella profunda en la arquitectura escolar de la España del siglo Xx. Conocido como el arquitecto de las escuelas fue director de la Oficina Técnica de Construcciones Escolares, que estrechamente vinculada a la Institución Libre de Enseñanza fue pionera en el tratamiento del espacio arquitectónico ${ }^{10}$. Bajo la máxima del espacio educa, la oficina proyectó una serie de prototipos educativos (1924). Estos prototipos pretendían dotar al rural de escuelas capaces de satisfacer unas necesidades educativas activadoras de la esperada revolución social que siguiendo el pensamiento de Ginés de los Ríos deberían proceder de la educación del pueblo.

\footnotetext{
${ }_{9}^{9}$ Puede consultar más información sobre este proyecto en: http://ferminblanco.com/web/?page_id=2297

${ }^{10} \mathrm{El}$ principio que posteriormente Loris Malaguzzi enunciaría sobre la importancia del tercer profesor.
} 

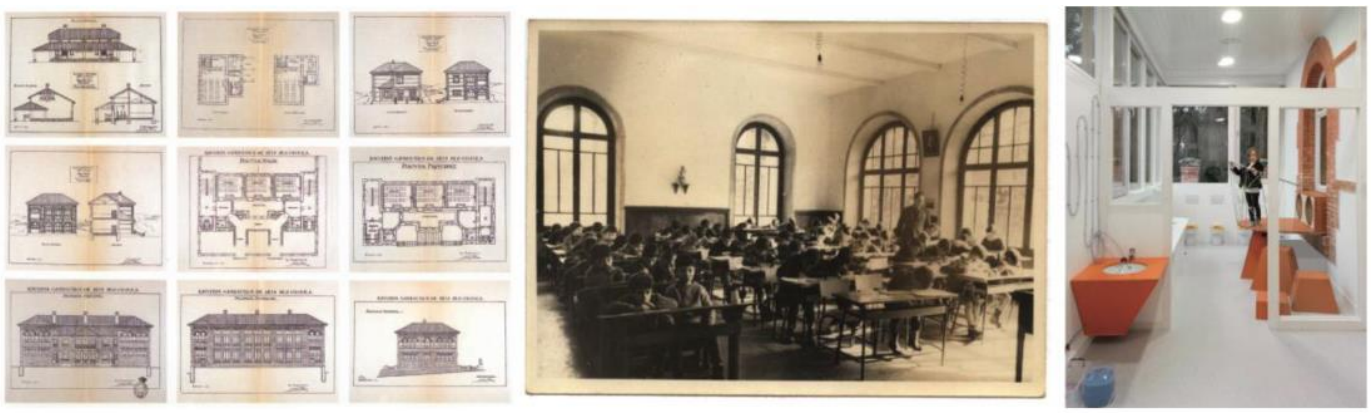

Figura 14. Izquierda: Planos de los distintos prototipos escolares propuestos por Antonio Flórez. Centro: Imagen del aula del CEIP Ortigueira en Santa Cruz de Ribadulla en 1968. Derecha: Aseo para aulas de infantil finalizado en 2016 Fuente: Elaboración propia.

Los modelos se proyectan siguiendo unas condiciones poblacionales y también climatológicas abstractas capaces de adaptarse a las diferentes circunstancias ambientales y topográficas del país. Entre 1920-1936 se construyeron varios de estos prototipos a lo largo de la geografía y en años posteriores, ya desaparecida la Oficina y enterrados los objetivos de la misma, sus formas pueden apreciarse en los proyectos de muchas de las escuelas levantadas siguiendo en parte su apariencia estética. Es sin embargo esta apariencia estética lo menos importante de lo que pretendía ser un auténtico avance en las conquistas del individuo. Bajo el peso de una larga dictadura se sacudieron los principios de una educación laica y científica que pretendía ser potenciadora de una modernización que tardaría en llegar. La década de los treinta es una época convulsa en Europa, de crisis generalizada y de difícil convivencia entre modelos.

Las escuelas proyectadas por la oficina compartían un doble componente que parece un sello de la personalidad del propio autor (según la opinión de la crítica) y también acorde a los difíciles momentos (Guerrero et al., 2002). Aunaban al tiempo la vanguardia higienista relativa a instalaciones, ratios profesor-alumno, metros cúbicos de aire, niveles de iluminación natural, ventilación y orientación, etc. Todos ellos elementos propios de las líneas emparentadas con la racionalidad de las vanguardias internacionales de principios de siglo. Sin embargo esta proa de lanza programática choca en lo arquitectónico con un estilo clásico, lleno de gestos académicos, cubiertas de teja con pronunciados aleros al estilo montañés, alzados de orden clásico con sus ritmos, sus combinaciones de ladrillo y mortero con zócalos de piedra. Todo ello genera una arquitectura "antigua" incluso convencional que mereció la agria crítica del GATEPAC. En su defensa podemos decir que resulta ciertamente digna, su presencia es representativa, institucional adjetivos éstos que realmente se echan en falta en la arquitectura escolar de la segunda parte del siglo Xx, (salvo excepciones obviamente).

La arquitectura escolar perderá esta dignidad en un momento dado, así como su carácter de pieza singular, urbana y pasará a caer en una deriva de anonimato de bajo coste y falsa practicidad de la que aún no nos hemos recuperado.

Desde el curso 2014/15 Sistema Lupo está involucrado en el proyecto "Repensando la escuela” en uno de los pocos prototipos educativos construidos en aquellos años (1927), concretamente el centro público, CEIP Ortigueira en Santa Cruz de Ribadulla. A Coruña. 
Gran parte de las metodologías empleadas y las conclusiones parciales pueden verse en el apartado de la página web de sistemalupo dedicada a lupo en el cole ${ }^{11}$.

Se trata de actualizar las metodologías de investigación y acción, las pedagogías progresistas (Ramón García, 2016) propugnadas desde la Institución Libre de Enseñanza y tratando de adaptarlas a nuestra época. Se propone un proceso participativo a toda la comunidad para tras un proceso de análisis del edificio y su entorno, acometer el proyecto y obra de la ampliación del centro uniendo los cuerpos de infantil y primaria así como el aprovechamiento y mejora del campo de juego y resto de instalaciones. Esta fase, que sería objeto de otro artículo, y excede los objetivos aquí comentados, está en desarrollo curso a curso con la colaboración de los alumnos, del claustro, las AMPAS, antiguos alumnos y las administraciones local y autonómica, es decir con el apoyo de toda la comunidad educativa.

\subsection{El paso a la acción real. Matta Clark. Anarquitectura}

Son muchos los arquitectos de formación que han decidido canalizar su actividad creativa a través del arte. Entre ellos la figura de Gordon Matta ocupa un lugar fundamental. Su trabajo en el campo de la escala y de la acción, la violencia de sus actos apoyado en el carácter efímero de las acciones, aportan una componente experiencial que resulta muy sugerente para la acción artística y su didáctica. Todo ello sumado al hecho de registrar sus acciones (foto y video) descartando la supervivencia de la obra física y reforzando el valor del proceso frente al fin último de la obra de arte objeto (figura 15).

La escala natural, es algo fascinante casi para cualquier rango de edad. Trabajar con bloques de gran tamaño que permitan construir por encima de nuestras cabezas es una experiencia sorprendente. Cuando Gordon Matta realizaba sus cortes y mostraba los interiores de edificios en ruina, trabajaba ese gran salto de escala que los arquitectos realizan desde la maqueta a la realidad pero en dirección opuesta, directamente a escala natural. Sustituyendo el cutter y tijeras por sierra circular. Su anarquitectura proponía reflexiones sobre la geometría, los cortes, la manipulación del positivo y del negativo no sólo en la realidad material sino también en fotografía en lo que supone además otro valor de su obra en lo referido a la conexión entre disciplinas.

Como parte de las acciones del primer año dentro del proyecto Repensando la escuela comentado en el punto anterior se utilizaron las estrategias de building cut como hilo didáctico durante un curso $^{12}$. Esta didáctica se extiende a todas las áreas de conocimiento, la profesora de inglés propuso visualizaciones de videos y documentales como apoyo durante sus clases, el profesor de música analizó la importancia del sonido en la obra de Gordon Matta, las cónicas se explicaron sobre el patio escolar y el resto de profesores adaptaron diferentes tareas al tema sirviendo como hilo conductor de una parte del curso aumentando el compromiso de los niños con el proyecto.

\footnotetext{
${ }^{11}$ Se puede consultar mas información del proyecto en: http://sistemalupo.ferminblanco.com/blog/category/repensandoa-escola/

12 Puede consultarse mas información sobre este proyecto en:

http://sistemalupo.ferminblanco.com/blog/category/repensando-a-escola/
} 
A día de hoy la antigua casa del maestro perforada por la intersección de un cono imaginario sirve de casa de juegos conquistada por los niños ${ }^{13}$.
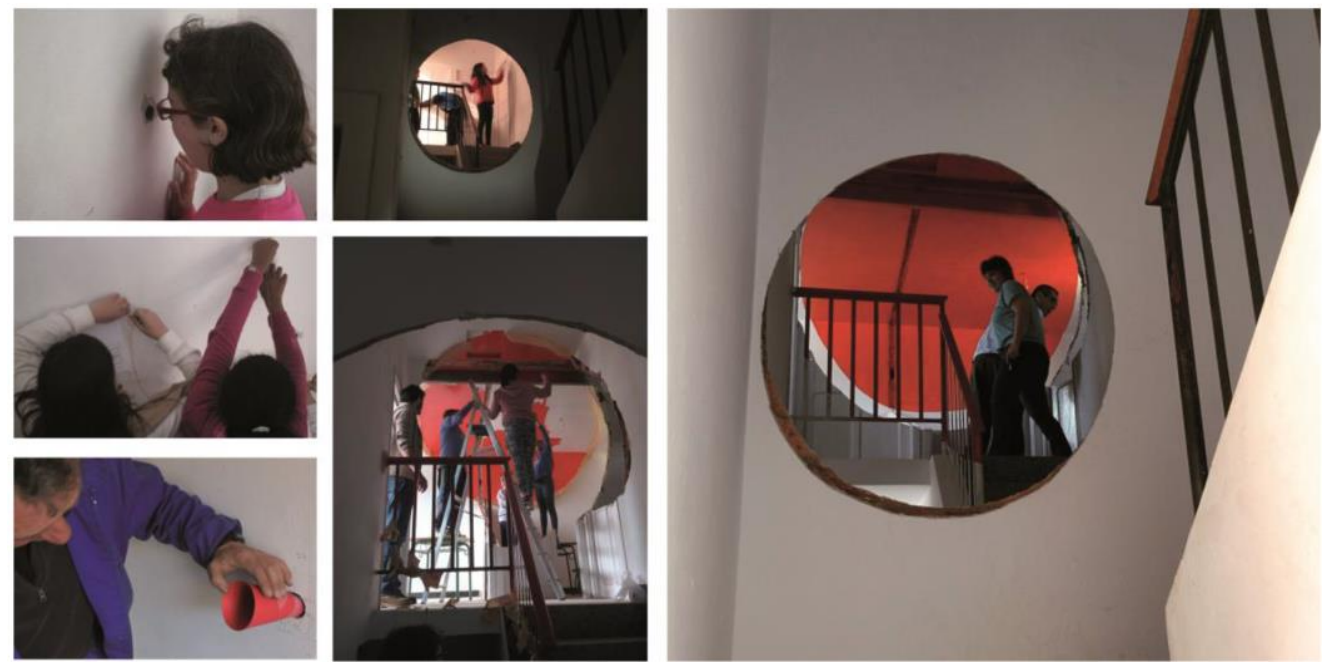

Figura 15. Proceso de apertura del cono realizado en el interior del edificio anteriormente dedicado a las viviendas de los maestros y que se encontraba en desuso. Actualmente el edificio es un espacio de juego que acoge la maqueta del centro elaborada por los propios alumnos y sobre la que se reflexiona acerca del futuro del colegio

Fuente: Elaboración propia.

\subsection{El autor. La enseñanza a partir de los maestros}

Uno de los métodos tradicionales de aprendizaje en la profesión de la arquitectura (el segundo oficio más antiguo del mundo según el profesor Ricardo Aroca) es sin duda la estrecha relación maestro-discípulo. Este método que se remonta al principio de las civilizaciones nos remite a los oficios, al aprender haciendo, a la masonería, al conocimiento oculto como valor a proteger (figura 16).

Hoy en día esta idea criptica donde el maestro acumula conocimiento y sólo lo cede a sus más estrechos colaboradores está en crisis. Hoy asistimos a la era del conocimiento compartido, los productos open source, las licencias creative commons, la participación en los procesos de diseño... Sin embargo el individuo sigue siendo un factor fundamental, siguen existiendo gurús, influencers u otros personajes de nombres más amables que guían procesos y proyectos. Sigue existiendo el maestro, aquel que nos indica caminos, que abre horizontes. En solitario o formando parte de equipos de trabajo, desde laboratorios o desde la empresa privada, en abierto o en cerrado pero ahí están los maestros.

Por este motivo, porque los maestros siguen existiendo y nos siguen motivando, desde 2013 desarrollamos una serie de didácticas basadas en las figuras que han hecho evolucionar nuestra profesión y creemos que en parte a las sociedades a las que han servido. En colaboración con el Centro Galego de Arte Contemporáneo de Galicia (CGAC) se desarrollan estos cursos para aprender de nuestros referentes, analizarlos siempre de modo crítico y aprender de sus aciertos y de sus errores. Bajo el título común

${ }^{13}$ Una selección de todo este trabajo puede verse en las revistas escolares de cada curso y en el blog del centro en: http://ceip-ortigueira.blogspot.com.es/ 
MIESes $+{ }^{14}$ cada edición busca figuras que hablen del Manifiesto, la Imaginación, la Experimentación y el Sentimiento. Las diferentes aproximaciones son o pretenden ser herramientas en manos de los participantes para eludir el dogmatismo y evitar visiones unidireccionales y cortoplacistas. La misma profesión ha sabido reconocer y dar cabida a expresiones tan diferentes como los manifiestos de Le Corbusier, Mies o Koolhaas, al carácter experimental de Frey Otto o Bucky Fuller, la creatividad de los Eames, Niemeyer o Utzon y la sensibilidad de SANAA o Lina Bo Bardi por citar algunos ejemplos. Un recorrido por su obra y su pensamiento nos hace visitar realidades y enfoques muy diferentes, países y momentos históricos, materiales, sociedades, guerras, golpes de estado, nos hacen en definitiva entender lo que fuimos y lo que somos ayudándonos a formar una visión crítica de nuestra realidad inmediata y proponiendo mecanismos para proponer, para investigar, para avanzar. Al mismo tiempo se ayuda en la difícil cruzada de poner en valor el patrimonio arquitectónico más reciente, el gran olvidado (figura 17).
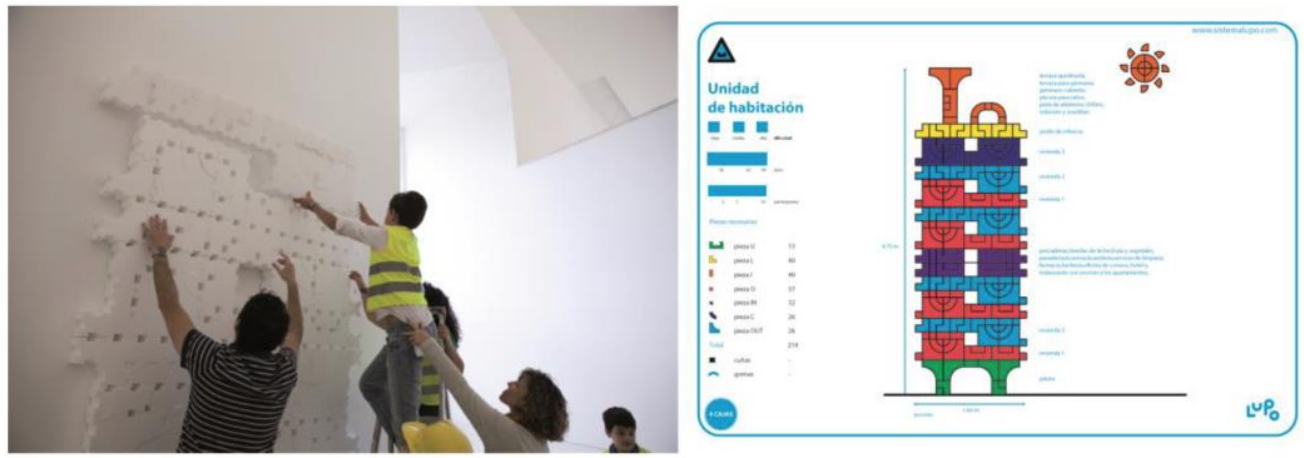

Figura 16. Taller didáctico MIESé+ sobre la figura de Le Corbusier. Parte de la didáctica sobre las unidades de habitación y sobre los procesos de prefabricación y montaje de las distintas unidades de vivienda que formaban el edificio

Fuente: Elaboración propia.
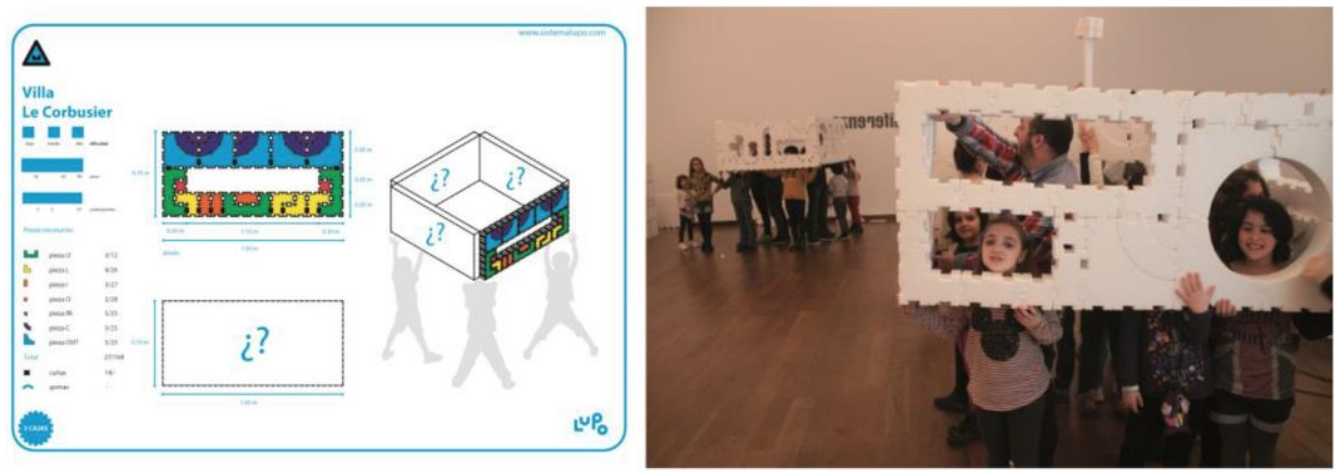

Figura 17. Taller didáctico MIESé+ sobre la figura de Le Corbusier. Didácticas basadas en los 5 puntos para una nueva arquitectura propuestos por el arquitecto suizo. Ficha propuesta y resultados creativos

Fuente: Elaboración propia.

${ }^{14}$ Puede consultarse mas información sobre este proyecto en: http://sistemalupo.ferminblanco.com/mies-e/ 


\subsection{Los romanos. A LVZ de Lvpo}

Romana por dentro y Neoclásica por fuera la Torre de Hércules ha llegado al siglo XXI manteniendo el mismo uso, $A$ Lvz de Lvpo supone un proyecto iniciático que dio origen a Sistema Lupo y que reúne una parte importante de los principios que aquí se proponen.

La construcción vertical en torre, es una aspiración del hombre desde antiguo y también del niño desde bebé. En este proyecto se trata de reproducir los problemas que plantea la construcción en altura, para una vez entendida la estructura, intervenir sobre ella de modo creativo.

Para ello se apostaba por un material; el popular porexpan en su versión no menos popular de cajas de pescado. Con ayuda de estas cajas se plantean actividades explicativas de distintas técnicas constructivas tanto romanas como actuales que los jóvenes pueden utilizar para la construcción. Como ejemplo de las posibilidades del sistema se realiza la construcción de un prototipo instalado en la escalera de Honor del ayuntamiento de A Coruña que reproduce la estructura romana a escala uno a cinco respecto a la original, y se realiza posteriormente con el mismo material una exposición donde se recrea la planta de la torre a escala mitad.

El objetivo final es doble, por un lado de conocimiento e interpretación del monumento y por otro lado intervención sobre su estructura. Al igual que Giannini en el siglo XVIII remodeló la estructura romana adaptándola en clave Neoclásica, las nuevas torres surgidas de la imaginación de los más jóvenes serán reflejo de nuestra época (figura 18).
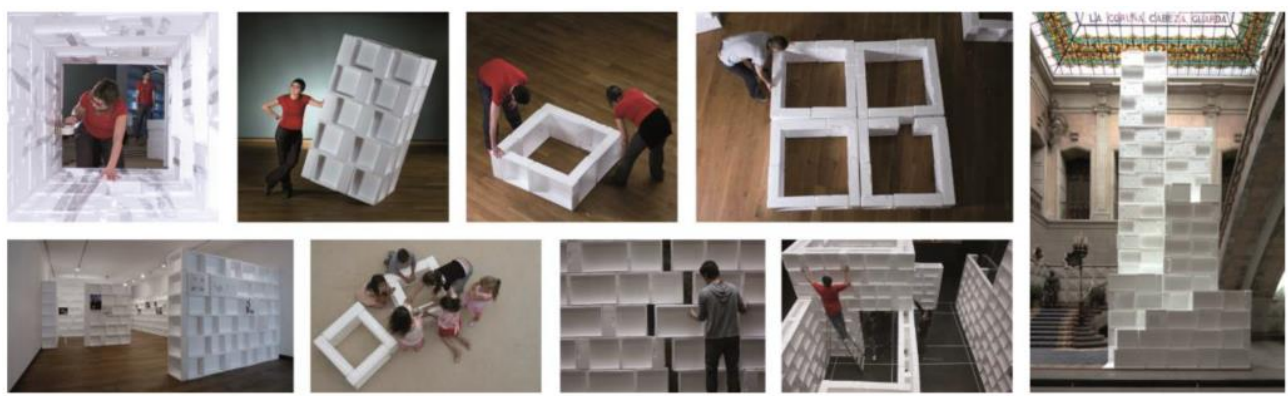

Figura 18. A Luz de Lupo es un posicionamiento desde la arquitectura en favor de la candidatura de la Torre de Hércules a patrimonio de la Humanidad. Se trata de una

exposición itinerante sobre el edificio donde la forma de la exposición se realiza siguiendo la geometría del faro romano, realizando itinerancias en la Fundación Luis Seoane, en el Ayuntamiento de A Coruña, en los distintos centros cívicos de la ciudad y en la Escuela de Arquitectura de A Coruña

Fuente: Elaboración propia.

Sobre el porqué del nombre del proyecto, Lupo fue un arquitecto romano de origen lusitano autor de esta torre. Se sabe poco de su vida pero lo cierto es que firmó a los pies de la torre de Hércules la obra con su propio nombre algo no muy habitual en el mundo romano donde el arquitecto queda generalmente en el anonimato al servicio del emperador.

Gaio Sevio Lupvs firmó seguramente con orgullo su obra, una obra que aún hoy mantiene el privilegio de ser el único faro del Imperio que sigue en uso. Desde 2009 la 
torre forma parte de la lista de obras Patrimonio de la Humanidad y esa universalidad de una obra local es un auténtico faro guía para el equipo ${ }^{15}$.

Años después la didáctica llevaría Sistema Lupo a otros puntos del Imperio y Roma ya no se separaría de la didáctica (ver Acueducto Mutante) ${ }^{16}$. Con esa practicidad que tenían los romanos, tan amigos del módulo, de la proporción y de la seriación. Auténticos precursores de la prefabricación en abierto de proyectos donde cada arquitecto fue capaz de elevar un acueducto, un teatro o una calzada según unas directrices pero todos diferentes, adaptados al terreno y circunstancias de cada comunidad local que hoy las siente como suyas y son auténticos iconos y símbolos indiscutibles.

Se decide dejar las cajas para el final de este decálogo de referencias como vuelta eterna a los orígenes así también los bloques en cada taller vuelven a la caja a la espera de ser abierta en próximas aventuras (figura 19).

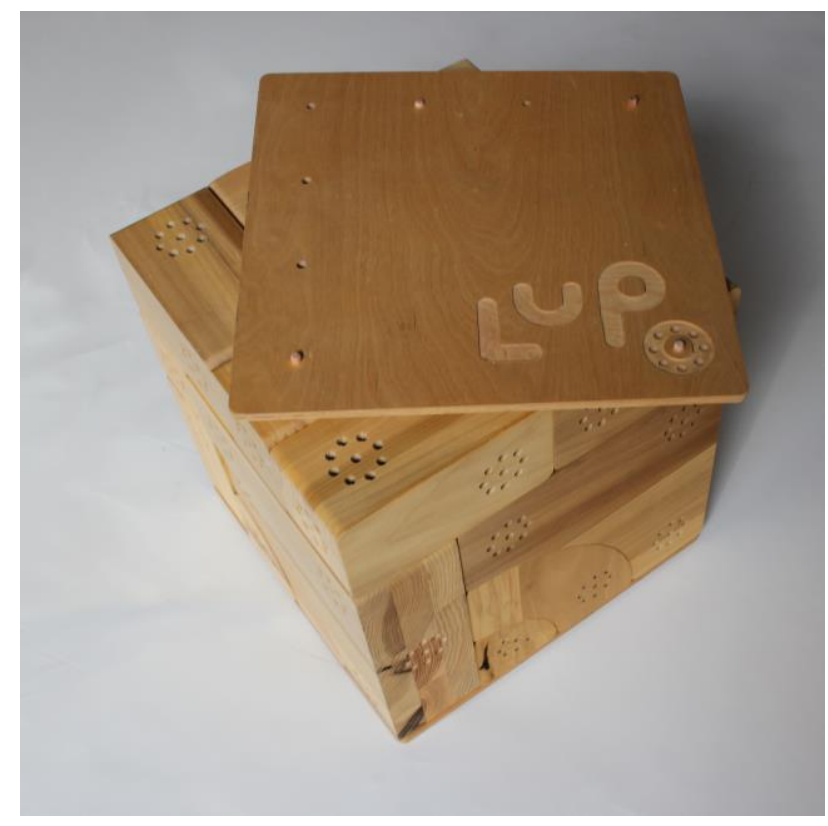

Figura 19. Caja de Timber Lupo

Fuente: Elaboración propia.

\section{Conclusiones finales}

Sistema Lupo nunca planteó metas a largo plazo, si pasados ocho años se sigue desarrollando esta actividad se debe sobre todo a una circunstancia fundamental y es que la metodología funciona, el juego, los bloques y el acto constructivo son estimulantes. Esto hace que los niños vuelvan a los talleres cada semana, que los museos renueven sus programas y que las franquicias no descataloguen los productos. Y mientras el proyecto se autoabastece con la actividad que genera se mantienen abiertas líneas de investigación que permiten establecer una serie de conclusiones.

\footnotetext{
15 Puede ampliar información sobre este proyecto en el siguiente enlace: http://www.ferminblanco.com/aluzdelupo/edu/etsac.html

16 Puede consultarse mas información sobre el proyecto Acueducto mutante en el siguiente enlace: http://sistemalupo.ferminblanco.com/blog/2016/02/26/acueducto-mutante/
} 
Dando por hecho las virtudes de estrategias educativas de mezcla de edades, cambio de roles, talleres familiares, presentación del proyecto final...factores todos ellos que generan dinámicas siempre positivas y dejando a un lado los beneficios propios del juego de bloques como son la capacidad de concentración, la visión tridimensional, la psicomotricidad, etc. Lo cierto es que el juego de bloques posee unas condiciones atávicas, inherentes al niño que lo hacen atractivo. No muestra flaqueza con el paso de los años, los niños siguen amontonado bloques y disfrutando con la libertad que les plantea el acto de construir e imaginar.

A partir de estas consideraciones pueden destacarse las siguientes conclusiones:

- Establecer pequeñas normas de conducta genera beneficios en el desarrollo del taller. El comportamiento del grupo requiere de unas condiciones ambientales amables, este ambiente es fundamental para el buen desarrollo de cualquier actividad pedagógica pero en los casos de trabajo con material de gran formato el orden es fundamental.

Por este motivo se establecen unos protocolos de recogida y selección del material en la llamada "cantera" que sigue a cada proceso de desmontaje.

- No se observan en los talleres patrones que diferencien el comportamiento de niños y niñas frente a los retos propuestos. Tal vez una ligera tendencia en algunos niños a trabajar de modo aislado fuera del grupo pero nada que genere patrón generalizable.

- Los patrones de comportamiento entre ambiente urbano y rural o comunidades grandes y reducidas son cada vez menos evidentes ${ }^{17}$, mientras que las diferencias derivadas de la capacidad económica de las familias es cada vez mayor (Ward, 1990a; 1990b). La capacidad de comunicación y trabajo en equipo está dañada en todos los casos por el abuso de la tecnología y la evidente falta de juego colaborativo o juego de calle o patio.

- En las edades comprendidas entre 4 y 9 años los niños reclaman lo figurativo, citando a Juan Bordes "el niño debe conquistar la figuración” y acompañarle en este desafío es parte del proceso.

- En paralelo al punto anterior se desarrollan actividades de "construir al natural", construcciones al exterior que favorecen los ejercicios de observación óptimos para edades de 9 a 12 años.

- El juego simbólico es complementario de la abstracción que genera el bloque y fase previa a las dos anteriores (Abad Molina, 2011).

- Al tratarse de una herramienta didáctica, su uso y aprovechamiento es adaptable a objetivos variables, ya sea en educación especial, en altas capacidades o en ámbitos universitarios (ver proyecto yin yang) ${ }^{18}$.

\footnotetext{
${ }^{17}$ Las diferencias ya observadas por Colin Ward en los años 70 y 80 parecen hoy ser menos evidentes, el efecto de la tecnología parece ejercer de agente homogeneizador.

18 Puede consultarse mas información sobre este proyecto en el siguiente enlace: http://sistemalupo.ferminblanco.com/blog/2015/03/31/3439/
} 
- El concepto juego es extensible a todas las edades (José Luis Linaza) y por tanto aplicable a la tercera edad o en juego adulto en general. En este sentido mantener una estética sobria de colores neutros o naturales (en el caso de la madera) favorece el tratamiento psicológico. En casos de demencia senil por ejemplo su uso no genera la humillante sensación de vuelta a la infancia entendida como incapacidad de ser útil.

- La gestión de la frustración tras la siempre temida demolición es una de los momentos más tensos y también estimulantes de un taller. El modo como el grupo se recupera de una demolición es un test de resiliencia tanto del individuo como del grupo.

- En la época de las tecnologías siguen estando en vigor las actividades manipulativas, es decir, que aun habiendo lupo digital y diseño $3 \mathrm{D}$, la gran mayoría de niños prefieren construir con piezas reales. De hecho, el formato de gran escala es la estrella de los talleres y los participantes muestran constantemente una inquietud por generar construcciones que les superen en altura o en las que se puedan meter dentro, casi como si quisieran volver a la cueva como refugio en el que sentirse a salvo.

- La satisfacción generada al superar un reto o la toma de decisión sobre la colocación de los bloques son actos de reafirmación de la personalidad tanto individual como del grupo.

En todo el proceso por supuesto se han cometido errores muchos derivados de la falta de experiencia inicial y otros fruto del atrevimiento o la excesiva carga de trabajo en un mismo taller. Experiencias como las comentadas de los bloques de diferentes colores terminaros por no ser exitosas tal y como se comentó en el capítulo correspondiente, y alguno de los intentos de producir Lupos experimentales resultaron poco rentables a la hora de industrializar debido al valor y aprovechamiento de los materiales o a las técnicas de fabricación propuestas.

El recortable Lupo DIY resulta dificultoso para las edades muy tempranas porque requiere de una ejecución cuidada para asegurar que las tolerancias entre piezas sean mínimas, su uso es sólo recomendable cuando la ejecución se deriva a los adultos perdiendo parte de su fuerza educativa.

El uso de disfraz (con chaleco y casco) no genera un acuerdo entre el equipo, si bien tiene un efecto positivo de ambientación entre los más pequeños puede llegar a resultar incómodo, incluso puede interpretarse como una manera de uniformar al personal lo que se encuentra muy alejado conceptualmente del propósito del proyecto.

Como conclusión puede afirmarse que toda esta experiencia demuestra a través de un proyecto de investigación, la posibilidad de desarrollar un método a través de la arquitectura y el juego apoyándose en fuentes heterogéneas y proponiendo al participante un rol activo y protagonista para pensar y aprender haciendo.

\section{Agradecimientos}

Sistema Lupo agradece a todos los que han participado en el desarrollo y aplicación de este proyecto de investigación aplicada. A todos los centros implicados y también a 
colectivos como, Arkiplay, Arquect, Arquitectives, Arquitectura Minúscula, Chiquitectos, Engalabernos, Hablar en Arte, Parada Facultativa, Nenoos y a los que se han quedado en el camino o han reorientado sus investigaciones.

También a la organización de los diferentes Encuentros de Educación e Infancia en el MNRS y a los seminarios de Juguetes y arquitectura de MediaLAb Prado de donde han salido tantos aprendizajes, y sobre todo a los niños y a sus familias.

\section{Referencias}

Abad Molina, J. (2011). El juego simbólico. Barcelona: Graó.

Bordes, J. (2007). La infancia de las vanguardias: Sus profesores desde Rousseau a las Bauhaus. Madrid: Cátedra.

Caillois, R. (2001). Man, play and games. Urbana, IL: University of Illinois Press.

Dewey, J. (1907). The school and society. Chicago, IL: University of Chicago Press.

Encinas Hernández, J. (2015). Arquitectura temprana: Estrategias didácticas de formación arquitectónica en el sistema educativo actual desde la enseñanza secundaria (Tesis doctoral, Universidad de Valladolid).

Guerrero, S., Górriz, V., Vega, J., Martínez de Castilla, N., Gil, D., Alarcó, B., ... y Linés, P. (2002). Antonio Flórez, arquitecto (1877-1941). Madrid: Residencia de Estudiantes de Madrid.

Habraken, N. J. (1999). Supports: An alternative to mass housing. Londres: Urban International Press.

Huizinga, J. (2012). Homo Ludens. Madrid: Alianza.

Linaza Merino, J. L. (2000). Jugar y aprender. Madrid: Pearson Educación.

Malaguzzi, L. (2011). La educación infantil en Reggio Emilia. Barcelona: Octaedro.

Munari, B. (2013). ¿Cómo nacen los objetos? Barcelona: Gustavo Gili.

Pestalozzi, J. E. (2009). Cómo Gertrudis enseña a sus hijos. Barcelona: PPU.

Rand, A. (2005). El manantial. Buenos Aires: Grito Sagrado.

Ramón García, M. (2016). How children understand their local environment: Visualization and participation. Madrid 2009-2014. Alcalá de Henares: Universidad de Alcalá de Henares.

Sutton-Smith, B. (1997). The ambiguity of play. Cambridge, MA: Harvard University Press.

Ward, C. (1990a). The child in the city. Londres: Bedford Square Press.

Ward, C. (1990b). The child in the country. Londres: Bedford Square Press.

\section{Breve CV del autor}

\section{Fermín González Blanco}

Es doctor arquitecto y profesor de Construction Systems en IE University. Ha realizado exposiciones, impartido cursos y conferencias relacionados con la arquitectura, el diseño y la didáctica por gran parte de la geografía nacional e internacional. Su tesis doctoral Los huesos de Fisac: la búsqueda de la pieza ideal recibió el primer premio en la VII Bienal Arquia/tesis 2010/11 y marca el inicio de una serie de proyectos de carácter 
divulgativo sobre la transferencia del conocimiento desde la técnica y el arte a la sociedad. Basado en la pedagogía activa y ahondando en la difícil relación teoría-práctica, en 2008 patenta Sistema Lupo, un sistema modular con fines didácticos que se industrializa en diferentes versiones y sirve como banco de experimentación del estudio. Los talleres y didácticas desarrollados desde esta multi-plataforma forman parte de un proyecto encaminado a profundizar en los cambios educativos y su adaptación al presente. ORCID ID: 0000-0001-9986-229X. Email: correo@ferminblanco.com, info@sistemalupo.com 